\title{
Viewpoint
}

\section{The Global Economic Crisis and Its Likely Impact on Population Activities}

The key lesson from the 1997-1999 economic crisis for the present economic crisis is that, in the field of social services generally and reproductive health services in particular, there is considerable resilience built into the population, partly because there have never been adequate social safety nets for the poor in developing Asian countries.

\section{By Gavin W. Jones*}

The global economic crisis of 2008-2009 calls to mind the Asian financial crisis of 1997-1999. Are there any lessons from that crisis that one ought to keep in mind as one considers the likely impact of the present crisis on the social sector in general and on reproductive health in particular?

First of all, we should be aware of the differences between those two crises, as they bear on the Asian and Pacific region - a region at the fulcrum of the earlier

\footnotetext{
* Professor, Asia Research Institute, National University of Singapore, e-mail: arigwj@nus.edu.sg
} 
crisis. The 1997-1999 crisis originated in Thailand, and spread quickly to other parts of Asia, notably Indonesia, Malaysia and the Republic of Korea. The current crisis is very different. It originated in the United States of America and spread around the world, seriously affecting the more open economies of East and South-East Asia - in particular Hong Kong, China; the Republic of Korea; Malaysia; Singapore; and Taiwan Province of China. The economies of all these countries and areas contracted significantly from the second half of 2008 until well into the first half of 2009. However, developing Asia as a whole has proved to be more resilient than earlier feared. China, India and Indonesia have maintained substantial economic growth, with rates for 2009 forecast at 8.2 per cent, 6.0 per cent and 4.3 per cent, respectively (ADB, 2009). Economic growth in developing Asia is expected to rise from 3.9 per cent in 2009 to 6.4 per cent in 2010.

There was concern at the time of the 1997-1999 crisis that it would unwind two decades of remarkable social and economic progress. Certainly it did lead to an untold amount of human misery, but not as great as newspaper headlines of the period led us to believe. Such headlines spoke of massive increases in poverty, unemployment, malnutrition and school dropouts. It was speculated that family planning programmes would collapse and fertility would rise dramatically. Infant and maternal mortality was expected to increase. A study that the author helped coordinate for the United Nations Population Fund (UNFPA, 1998; Jones, Hull and Ahlburg, 2000) found that those effects were neither as dramatic nor as easy to monitor as some of the public debate implied. The most serious social and demographic problems appeared to be embedded in chronic weaknesses that had become entrenched in times of economic growth, and not so much caused by, but rather exposed by, the crisis.

While economic crises are devastating for many, for some they bring windfall gains and new opportunities, such as (net) food producers in many parts of Indonesia, who benefited from increasing food prices. For the majority of Indonesians who were adversely affected by the crisis, individuals and families were clearly very resourceful in dealing with the situation (Frankenberg, Smith and Thomas, 2003). Wages for the unskilled in urban areas decreased more than for those in rural areas. Some urban unskilled workers left to seek work in rural areas, and household composition data suggest that many of them joined middleincome or higher-income households in rural areas, which increased in average size. Many workers, particularly the self-employed, increased their hours of work. Households cut back spending on deferrable items, and many households spent their wealth - including selling gold, whose price in Indonesian rupiah rocketed as the rupiah collapsed. 
Of course families and individuals had little choice but to be resourceful. The lack of social safety nets in the crisis-affected countries meant that families and individuals knew from past experience that they were largely on their own in dealing with the crisis and its aftermath. Social safety net programmes were introduced in Indonesia and Thailand with massive international assistance, but the task of identifying and targeting the poor without disrupting home-grown community and family support was daunting. All the more so as social safety nets "involve immense dangers of misallocation of resources through failure to identify the appropriate recipients, unwieldy bureaucracy and corruption" (Jones, Hull and Ahlburg, 2000: 59).

In Thailand and Indonesia, children were most vulnerable to dropping out of school at the transition points between stages in the system. The crisis did not lead so much to declines in enrolment ratios as to the failure of lower secondary enrolment ratios to maintain their earlier strong upward trend (Jones and Hagul, 2001; Warta Cimu, 2001).

Budget cuts became necessary in many crisis economies to make up for lower revenue and to increase public savings. Rethinking budgetary priorities was also needed in order to preserve key basic social services. The challenge was also to improve efficiency in the provision of those services, consolidating programmes to reduce wastage and leakage, and to get more output from fewer resources. Better targeting of public resources to the real poor or the poorest regions was necessary, but statistical measurements of who the real poor or the poorest regions were proved to be a headache. In the case of the Indonesian scholarships and grant programmes, only 63 per cent of the scholarships designed to assist poor students were given to students in the two lowest household expenditure quintiles (Jones and Hagul, 2001, table 5).

In the field of reproductive health, quick action and international support in the first months of the crisis prevented some of the worst outcomes that had been feared, particularly relating to the supply and affordability of contraceptives. Governments reiterated their commitment to safe motherhood and child survival in their health-care budgets. Mechanisms were also developed to ensure services for the poor. Issues related to generic drug prices and availability were addressed although there certainly remained problems. General health services suffered in Indonesia and the Philippines - hardly a situation in which reproductive health services could flourish. Indonesian contraceptive supplies were maintained to a large extent through support from a number of donor agencies, though the adequacy of staff skills to meet the challenge of service delivery in times of crisis 
remained an issue. In the Philippines and Thailand, the problems faced in the reproductive health field were not so much crisis-induced as structural and bureaucratic, compounded in the Philippines by opposition to reproductive health services by congressional and religious opponents (Jones, Hull and Ahlburg, 2000: 54-56).

Claims that both birth and death rates would rise as a result of the financial crisis proved to be misplaced. Of course little hard evidence was available at the time to monitor demographic impacts of the crisis, and in such a situation only speculations could flourish. But over time, survey evidence showed that the crisis did not lead to any measurable increase in either fertility or mortality rates in any of the crisis-hit countries. (For fertility estimates for Indonesia - the country hit most severely by the crisis - see Hull and Mosley, 2008).

The key lesson from the 1997-1999 economic crisis for the present economic crisis is that, in the field of social services more generally and reproductive health services in particular, there is considerable resilience built into the population, partly because there have never been adequate social safety nets for the poor in developing Asian countries, and therefore the reliance on household and community support in times of difficulty is entrenched in the society. This should not be used as an argument against developing more adequate social security programmes, though it does suggest caution in ensuring that positive community mechanisms are not undermined by these programmes. Over time, income maintenance programmes for the elderly and other forms of social support have been developing in Asia, though more comprehensively in the wealthier countries such as Japan, the Republic of Korea and Singapore than in the lower income ones (Takayama, 2005). Emergency measures to ensure adequate supplies of medicines and contraceptives may be required in the early stages of an economic crisis, but typically what a crisis does is to expose and highlight shortcomings built into the system. In the cases of both the Philippines and Indonesia, administrative and political decentralization has greatly changed the nature of the issues they faced during the crisis of 1997-1999. Such decentralization may lend itself to innovative and more locally focused ways of dealing with the issues; it may also make progress both more "spotty" and harder to monitor than in centralized administrations. 


\section{References}

Asian Development Bank (ADB) (2009). Asian Development Outlook 2009 Update: Rebalancing Asia's Growth (Manila, ADB, September).

Frankenberg, Elizabeth, James P. Smith and Duncan Thomas (2003). "Economic shocks, wealth and welfare", The Journal of Human Resources, vol. 38, No. 2, pp. 280-321.

Hull, Terence H. and Henry Mosley (2008). "Report on revitalization of family planning in Indonesia", report to the National Family Planning Coordinating Board (BKKBN) with support from the United Nations Population Fund.

Jones, Gavin W., Terence H. Hull and Dennis Ahlburg (2000). "The social and demographic impact of the Southeast Asian Crisis of 1997-1999”, Journal of Population Research, vol. 17, No. 1, pp. 39-62.

Jones, Gavin W. and Peter Hagul (2001). "Schooling in Indonesia: crisis-related and longer-term issues", Bulletin of Indonesian Economic Studies, vol. 37, No. 2, pp. 207-231.

Takayama, N., ed. (2005). Pensions in Asia: Incentives, Compliance and Their Role in Retirement (Tokyo, Maruzen Co. Ltd.).

United Nations Population Fund (UNFPA) in collaboration with the Australian National University (1998). South-East Asian Populations in Crisis: Challenges to the Implementation of the ICPD Programme of Action (New York, UNFPA).

Warta Central Independent Monitoring Unit (CIMU) (2001). "The effects of the scholarship program at the household level" (Jakarta, CIMU, November). 



\section{Meeting the Goals of the ICPD Programme of Action: Key Challenges and Priorities for Asia and the Pacific, Fifteen Years $\mathrm{On}^{1}$}

There is a lack of or even a declining importance given by planners and policy makers in many countries of the region to family planning, as it is seen mainly as a means of reducing fertility and not as a cost-effective strategy to improve maternal and child health.

By K.S. Seetharam and Geoffrey Hayes*

\section{ICPD Programme of Action and the MDGs}

The International Conference on Population and Development (ICPD), held at Cairo in 1994, adopted a comprehensive, and in many ways path-breaking, Programme of Action that has led to the reorientation of population policies and

* Consultants, International Council on Management of Population Programmes (ICOMP), Kuala Lumpur, e-mail: icomp@icomp.org.my. 
programmes worldwide. The Programme of Action called for a rights-based approach to the formulation and implementation of population policies and programmes that would be responsive to individual needs and aspirations.

ICPD and the global conferences of the 1990s laid the foundation for the adoption of the Millennium Declaration in 2000 by 147 heads of State and Government, and 191 nations and its subsequent eight related goals, known as the Millennium Development Goals (MDGs). It is widely agreed that the achievement of the goals of the ICPD Programme of Action is central to the achievement of the MDGs.

The 20-year Programme of Action adopted at ICPD (referred to as the ICPD PoA or the Cairo Agenda) is very comprehensive and includes a number of objectives, actions and goals relating to a broad set of issues of population and sustainable development; reproductive health including family planning; and gender equality, equity and the empowerment of women.

The United Nations General Assembly convened a special session from 30 June to 2 July 1999 to take stock of the progress accomplished over five years in implementing the ICPD Programme of Action and based on the lessons learned adopted "Key Actions for the Further Implementation of the ICPD PoA" (United Nations, 1999) that included additional goals and objectives.

Taken together, the ICPD Programme of Action and Key Actions adopted at the five-year review (ICPD+5) called upon countries to achieve the following quantitative goals (rephrased and condensed in UNFPA, 2002):

- Universal access to reproductive health care, including family planning and sexual health by 2015 (ICPD PoA paragraph 7.6);

- Halving the 1990 illiteracy rate for women and girls by 2005 (ICPD+5 paragraph 35c);

- Enrolling 90 per cent of boys and girls in primary schools by 2010 and ensuring universal access to primary education by 2015 (ICPD PoA paragraph 11.6 and ICPD +5 paragraph 34 );

- Reducing infant mortality to below 35 deaths per 1,000 live births and under-five mortality to below 45 per 1,000 by 2015 (ICPD PoA paragraph 8.16);

- Reducing maternal mortality rates to half the 1990 levels by the year 2000, and by half again by 2015 (ICPD PoA paragraph 8.21); 
- Increasing life expectancy at birth to 75 or more by 2015; those countries with the highest levels of mortality should aim to attain at least 70 by 2015 (ICPD PoA paragraph 8.5);

- Reducing the unmet need for contraception by half by 2005 and eliminating it altogether by 2015 (ICPD +5 paragraph 58);

- Ensuring that 60 per cent of primary health-care and family planning facilities offer a wide range of services by 2005 , including family planning, obstetric care, and prevention and treatment of reproductive tract infections including sexually transmitted diseases (STDs); and that 80 per cent do so by 2010 (ICPD+5 paragraph 53);

- Ensuring that 90 per cent of all births are assisted by skilled attendants by 2015 (ICPD+5 paragraph 64); and

- Reducing HIV infection in youth by one quarter by 2010; guaranteeing that 95 per cent of 15-24 year olds have access to information and services by 2010 to help them avoid HIV infection - including condoms, voluntary testing, counselling and follow-up (ICPD+5 paragraph 70).

In addition the ICPD Programme of Action includes a number of objectives that are referred to in the various sections that follow.

The aim of this paper is to highlight the progress that has been made by the countries of Asia and the Pacific towards achieving the goals and objectives of the ICPD Programme of Action during the 15 years since its adoption and the challenges and priorities that need to be addressed in the years ahead to accelerate progress towards these goals. The paper draws upon the findings of prior reviews including the recent regional reviews conducted by the Economic and Social Commission for Asia and the Pacific (ESCAP) and the United Nations Population Fund (UNFPA) to commemorate 15 years since ICPD.

\section{Asian and Pacific context}

\section{Population dynamics}

The population of Asia (excluding North and Central Asia, but including the developed countries) estimated at 3.9 billion in 2009, is projected to increase to 4.5 billion by 2025 , representing an average increase of 37 million annually. The region as a whole has recorded a significant decline in the rate of growth of population since 1990 from about 1.8 per cent in 1990 to 1.0 per cent in 2009 . The decline is reflected in all the subregions and in most countries. For example, 
the rates declined from 1.3 to 0.5 in East and North-East Asia, from 2.0 to 1.2 in South-East Asia, and from 2.3 to 1.5 in South and South-West Asia (ESCAP, 2009a).

The decline in the rate of population growth, contributed mainly by the developing countries of the region, is due to declines in fertility even as mortality declined, albeit at a slower pace. For example, the total fertility rate (TFR) declined from 4.6 in 1990 to 2.8 in 2009 in South and South-West Asia; from 3.5 to 2.2 in South-East Asia and from 2.3 to 1.7 in North and North-East Asia while expectation of life at birth increased from 58 to 65,62 to 71 , and 71 to 74 , respectively, in the three subregions. While TFRs vary among countries, it is below three in most countries and the declining trend is likely to continue, even in countries where the rate remains high.

Tables $1 \mathrm{a}$ and $1 \mathrm{~b}$ also show variations in mortality, as reflected by the expectation of life at birth among the countries of Asia. While China, Indonesia, the Islamic Republic of Iran, Malaysia, the Philippines, Sri Lanka, Thailand and Viet Nam are likely to achieve a life expectancy of 75 years by 2015, many other countries will attain only the target of 70 years by 2015 . However, for large segments of some populations, particularly in South Asia, attaining the goal of 70 years by 2015 will prove difficult.

As a result of declines in mortality and fertility, particularly the latter, the age structure of Asian populations has also undergone change with the proportion of population below age 15 declining from around 26 in 1990 to 20 in 2000 in North and North-East Asia, and from 37 to 28 and 39 to 32 in South-East Asia and South and South-West Asia, respectively. The proportion of the population above age 65 has increased significantly (from 6 to 14 per cent during 1990-2009) in East and North-East Asia and from 4 to 8 and 9 per cent in the other two subregions. Those changes manifest themselves in an increase in the working age population and declining dependency ratios, particularly in the countries of South-East Asia and South and South-West Asia which is conducive to increased savings, investment and economic growth.

Although the sea area surrounding the Pacific islands is immense, the total population of that subregion was only about 9.7 million in 2009 and the rate of population growth has been declining steadily since the 1990s. The population growth rate in the Pacific as a whole is currently 1.9 per cent per year. The high growth countries are in Melanesia, with the Solomon Islands having the highest rate ( 2.7 per cent), followed by Vanuatu ( 2.5 per cent) and Papua New Guinea 


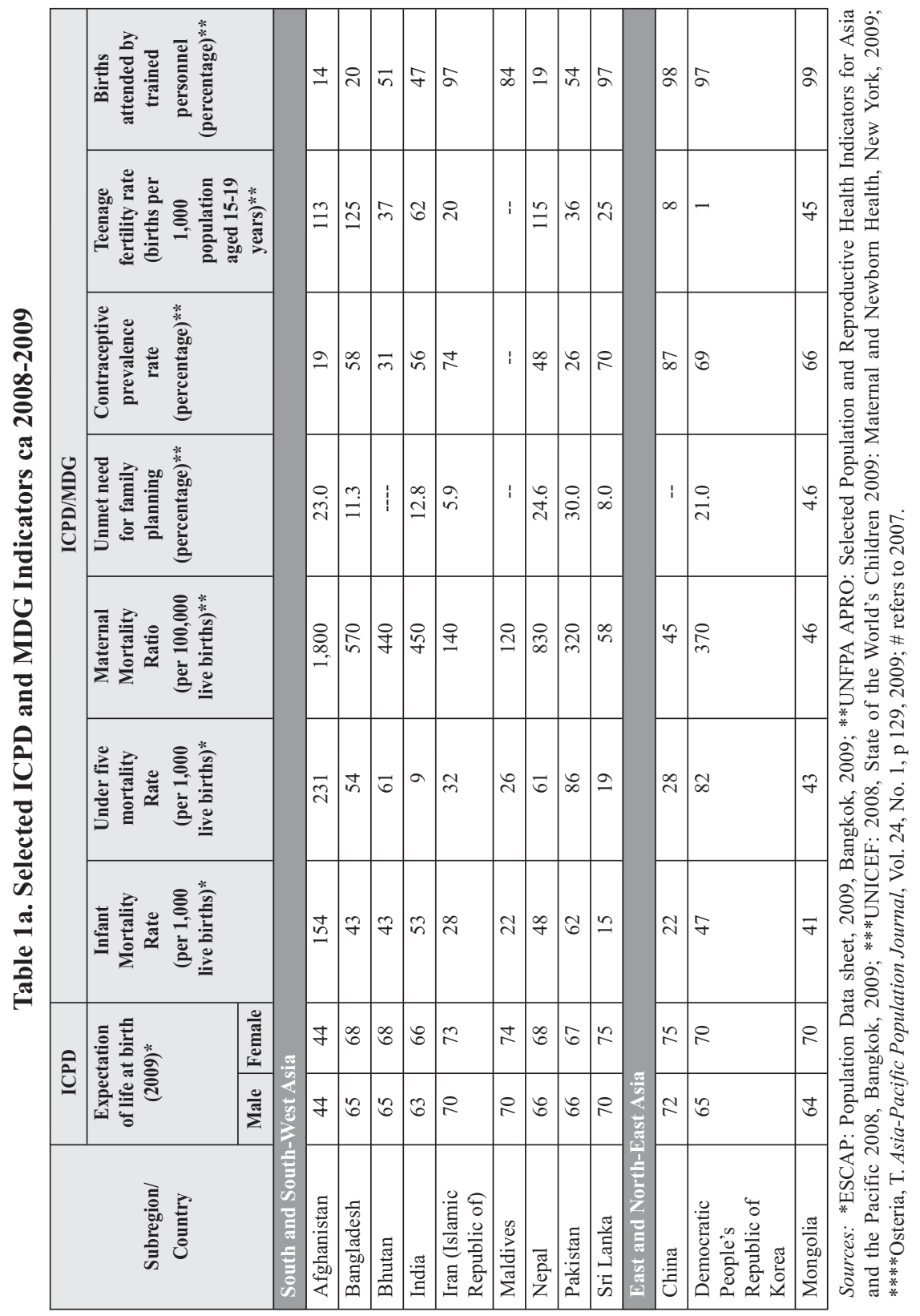




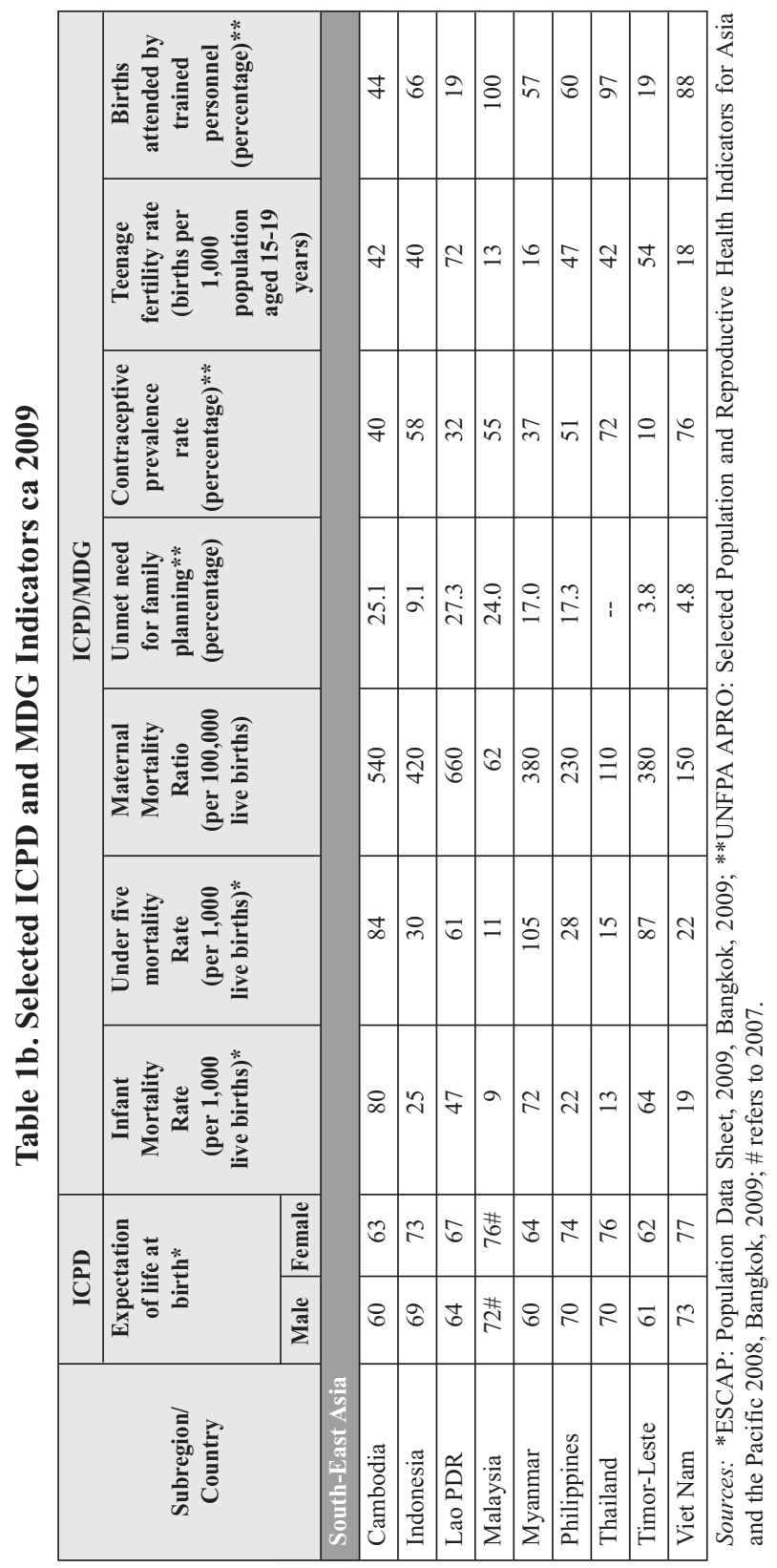




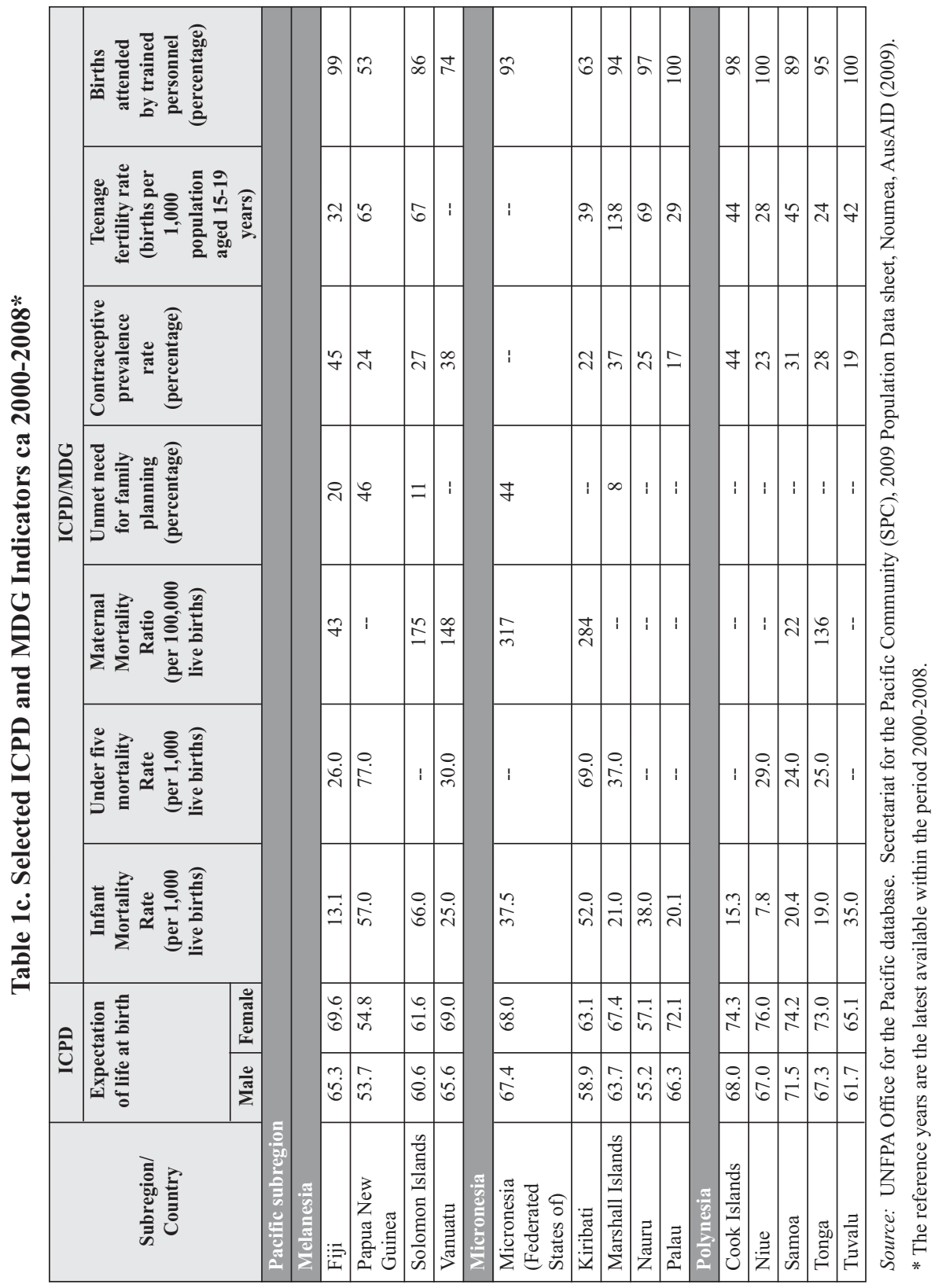


(2.2 per cent). Growth rates are 1.4 per cent in Micronesia and 0.8 per cent in Polynesia, with some Polynesian countries experiencing negative growth due to net emigration.

The fertility transition has been underway for several decades in Micronesia and Polynesia and more recently in Melanesia but still has a long way to go. Several countries across the Pacific still have a TFR between 4 and 5. In most Micronesian and Polynesian countries, low population growth is achieved by emigration while a natural increase has remained relatively high. Very few countries and areas in the Pacific have achieved moderate or low population growth by means of low rates of fertility rather than emigration and these are mainly dependent territories.

Also, the pace of mortality decline in the Pacific has been slow and in some countries life expectancy has stalled. Only four Pacific island countries had achieved the ICPD target of above 70 years by 2005 and these were all in Polynesia. Several Micronesian countries are close to the 2005 target but do not appear likely to achieve the ICPD target of above 75 years by 2015. A number of countries fall well short of the 2005 ICPD target, most notably Papua New Guinea, which had a life expectancy of only 54 years in 2000 - the latest year for which data are available (table 1c).

\section{Economic and social change}

Many countries in Asia have been experiencing rapid economic growth during the last two decades. The high rate of growth of gross domestic product (GDP) experienced by a few countries - the Asian tigers - during the 1970s and 1980s, has spread to other countries, most notably China and India - the two most populous countries in the world, as they began the process of trade liberalization and embraced free market principles. The 1997 Asian financial crisis and the global meltdown of 2008 have had their impact on the rate of growth and its potential for reducing poverty in the countries of the region. Yet, they remain remarkably resilient and Asian economies have recovered sooner than previously expected.

Many Asian countries have also recorded significant reductions in the level of poverty, as measured by the proportion of population living on less than $\$ 1.25$ a day, since 1990. The decline has been dramatic (from 54.7 per cent in 1990 to 16.8 per cent in 2005) for the countries of East Asia, while it has been modest (51.7 per cent to 40.3 per cent during the same period) in South Asia. The total 
number of people living below the poverty line also declined from 1.45 billion to 912 million during the same period, owing mainly to rapid reductions in those numbers in China and South-East Asia. However, if the threshold is raised to $\$ 2.00$ per day, the number and percentage of people living below this threshold will be considerably higher-38.7 per cent in East Asia and the Pacific and 73.9 per cent in South Asia - reflecting the persistence of poverty in the region. Moreover, even as the percentage of population living below $\$ 1.25$ and $\$ 2.00$ has declined, the actual numbers living below those thresholds have increased in South Asia, during the same period (Jones, 2009).

Improvements in education, access to basic health services, nutrition and access to clean water have also taken place in most Asian countries during the same period. However, large sections of the population in South Asia, and the disadvantaged and vulnerable population groups in a number of other countries are still deprived of, or only having very limited access to these basic services, such as clean water and sanitation (see tables $2 \mathrm{a}$ and $2 \mathrm{c}$ ).

Women in Asia are becoming educated, marrying later, entering the formal labour market and getting involved in public life in larger numbers than ever before, as indicated in later sections. Yet, in many Asian countries women continue to be subjected to age-old prejudices and biases.

In contrast to many Asian countries, economic growth in the Pacific islands has been slow over recent decades (AusAID, 2009). In several countries, GDP growth has been lower than population growth, resulting in a decline in per capita GDP.

In several Polynesian countries, migrant remittances contribute significantly to the gross national product (GNP) and help to maintain per capita incomes during difficult economic conditions at home. In general, migrant remittances have improved the distribution of income and alleviated poverty (World Bank, 2006) so the decline in migration opportunities caused by the current global economic crisis may worsen poverty at home.

In the context of MDG-based development planning in the Pacific islands, extreme poverty has been replaced by the "basic needs" concept and "basic needs poverty lines" (Abbott, 2006). The proportion of the population falling under the basic needs poverty line in Pacific developing countries and territories ranges from 13 per cent to 50 per cent (AusAID 2009). 


\section{Assessment and review of progress since ICPD}

\section{Population, sustainable development and poverty}

\section{Population and poverty}

Poverty reduction is an important goal of the United Nations Millennium Declaration and rapid economic growth is central to poverty reduction - as evidenced by the low incidence of poverty in the more advanced countries of the region. However, available evidence suggests that the declining incidence of poverty in Asian countries is also closely correlated with reductions in fertility and population growth, advances in education, improvements in health, increasing urbanization and women's greater participation in economic activity.

Poverty is caused by a multitude of factors and low levels of health, high fertility and a high rate of population growth are important among them. This is fully recognized in the ICPD Programme of Action as it calls upon countries to "raise the quality of life through population and development policies and programmes aimed at achieving poverty reduction, sustained economic growth in the context of sustainable development" (paragraph 3.5).

Countries in Asia are well aware of the relationship between high fertility and population growth and their impact on poverty, and those with a high rate of population growth have continued their policies and programmes aimed at reducing fertility and population growth. However, as discussed in the preceding section, high levels of poverty are still prevalent in large parts of South Asia encompassing Afghanistan, Bangladesh, India, Nepal and Pakistan, and in a few other countries, namely Cambodia, the Lao People's Democratic Republic and Timor-Leste, and among ethnic minorities and vulnerable population groups across Asia. While improving access to education and health services, including reproductive health and family planning services, is critical to getting people out of poverty, efforts to date in these countries are not promising. This is reflected in the following statement: "An objective assessment of the provision of public facilities for education and health in many countries of the ESCAP region would have to conclude that such provision not only does not serve to narrow the wide gaps between the welfare of the poor and that of other sections of the population, it actually serves to widen them" (Jones, 2009).

A similar view was expressed by Dr. Purnima Mane, Deputy Executive Director of the United Nations Population Fund (UNFPA), in her statement at the 
opening session of the Asia-Pacific High-level Forum on ICPD at 15 in September 2009: "People who have the most resources — whose needs for health care are often less - tend to consume most care, whereas those with the least means and the greatest health problems consume the least. Data shows that public spending on health services most often benefits the rich rather than the poor in high- and low-income countries alike." She added that addressing inequities should therefore be a top priority (Mane, 2009).

In the Pacific islands, sustained economic growth has proven to be elusive over the past two decades. While some countries have achieved positive GDP per capita growth in some years, growth has frequently been a result of a shortterm resources boom or a temporary jump in tourist arrivals. The type of rapid and sustained GDP growth that has occurred in many Asian countries as a result of a development strategy focused on "export-driven" manufacturing has not occurred in the Pacific islands.

Poverty reduction has not been a major feature of development planning in the Pacific islands until recently. For MDGs to become accepted at the country level as a framework for development planning, the concept of poverty had to be recast as "basic needs poverty", "poverty of opportunity" or "poverty of access" to basic social services, education and employment (Abbott, 2006).

In view of the above, a pro-poor approach to the provision of basic services, including improving access to reproductive health/family planning services, should be a policy and programme priority to alleviate poverty and improve the quality of life.

\section{Infant and child mortality}

The Millennium Development Goals Report 2009 (United Nations, 2009) reported progress in reducing child mortality in all the subregions of Asia. Yet, it notes that many countries in South Asia have made little or no progress. According to ESCAP estimates (ESCAP, 2009a; see tables), infant and child mortality in East and North-East Asia and South-East Asia are well below the respective targets of 35 and 45 to be reached by 2015 . By contrast, estimates of infant and under-five mortality in South Asia are well above the targets, averaging 54 and 78, respectively.

Countries with infant and under-five mortality well above target levels include Cambodia, Myanmar and Timor-Leste in South-East Asia, and Afghanistan, parts of India, Nepal and Pakistan in South Asia. Yet available evidence suggests that 
infant mortality rates are much higher among the poorest segments of the population (Jones, 2009), which is also likely to be true among children as most deaths among them are due to avoidable causes. Inequities in the provision of health care and other social services contribute to the persistence of high infant and child mortality among the poor. Reduction in those inequities through a pro-poor approach should, therefore, be a priority because greatest gains in infant and child survival depend on effectively reaching the poorest and most marginalized, who suffer the greatest burden of disease (UNICEF, 2009).

Infant mortality has been declining in all Pacific island countries and territories since the 1990s, although the pace of decline has varied. The ICPD target for infant mortality rate (50 per 1,000 in 2000) was achieved in all but two countries, yet very few countries achieved a one third reduction between 1990 and 2000. Again, only two countries - Kiribati and Papua New Guinea-fell short of the 2005 target and these are also the only ones that may have difficulty achieving the 2015 target. All other Pacific island countries have already achieved the ICPD goal of reducing infant mortality rate to below 35 by 2015 (see table 1c).

The ICPD goal for the under-five mortality rate (U5MR) by 2000 and 2005 were achieved in most Pacific countries by 2005 or earlier. Achieving the MDG target of reducing the U5MR by two thirds between 1990 and 2015 is more difficult because the normal pattern in the mortality transition is for the pace of decline to slow down as the U5MR reaches lower levels, and several Pacific countries already had reached low levels by the year 2000. Nevertheless, several countriesincluding the Marshall Islands, Vanuatu and most countries and areas in Polynesia- are on track to achieve this target. The larger Melanesian countries of Fiji, Papua New Guinea and the Solomon Islands may not be able to achieve the necessary rate of reduction. Only two countries-Kiribati and Papua New Guinea-are not presently on track to achieve the ICPD goal for under-five mortality by 2015 .

Key factors that explain countries' performances with regard to under-five mortality in the Pacific subregion include immunization coverage and access to an improved water supply and sanitation.

\section{Population ageing}

Decline in fertility rates together with declining mortality is transforming the age structure of the populations in most countries of Asia, and some in the Pacific. Advanced stages of age structure transition will inevitably result in population 
ageing, a process whereby the population at older ages (60 and over) will begin to comprise an increasing share of the total population. For instance, it is estimated that older persons will constitute about 15 per cent of the total population by 2025 and by 2050 it is expected to increase to 25 per cent for the region as a whole. Furthermore, an increasing number of countries in Asia will enter this stage and population ageing, which was until recently limited to the more advanced countries, will become more rapid and represent an important feature of population dynamics of all countries in the not too distant future.

To address this emerging issue, the ICPD Programme of Action has called on countries "to develop systems of health care as well as systems of economic and social security in old age, where appropriate, paying special attention to the needs of women". International efforts to respond to the challenges posed by population ageing culminated in the adoption of the Madrid International Plan of Action on Ageing (MIPAA) at the Second World Assembly on Ageing in 2002. This Plan has since become the basis for action on population ageing.

The 10-year review of the implementation of ICPD Programme of Action undertaken by ESCAP in 2004 has indicated that countries in Asia have taken a number of measures to address the needs of older persons (United Nations, 2004 p. 13-14). The five-year review of MIPAA undertaken by ESCAP in Macao, China, from 9 to 11 October 2007 highlighted various national initiatives as well as the progress accomplished in developing plans, policies and programmes and in setting up institutional mechanisms to prepare for an ageing society (ESCAP, 2007).

In the Pacific, most countries had youthful populations with a median age of about 17-19 years up until the 1970s. The proportion of youth in those populations has remained relatively high due to population momentum, but as in Asia, the mortality and fertility transitions have begun to have an impact on age structures and several countries now have ageing populations. Where ageing is occurring, Governments in the Pacific have yet to examine in detail the implications for health care and social welfare. As in Asia, most older persons are cared for in a family setting, but this arrangement will come under increasing strain in the coming years as higher proportions of the elderly population reach 80 years of age and over and suffer from disability, infirmity, chronic illness and face a shortage of caregivers owing to the impact of emigration.

Thus, both regionally and at national levels, efforts are being made to place the issue of ageing on the agenda for development. Regional review of MIPAA 
has shown that the initiatives taken by countries include developing policies and plans, establishing national mechanisms, and raising public awareness of the benefits of healthy lifestyles and active ageing. Countries are also taking measures to provide social security and social protection to older persons.

A number of countries in Asia and the Pacific have collected data on older persons and many have undertaken studies on ageing and related issues. There have also been comparative studies on ageing in the countries of South, South-East and East Asia, and the Pacific. Those studies are providing valuable information for policy development and for initiating programmatic responses (Mujahid, 2006 and Mujahid and Siddhisena, 2009).

The following is a list of priority actions that must be considered by Asian and Pacific Governments and development partners in order to prepare for an ageing society:

1. Expand the coverage of social security systems to include those not covered by formal system; assess the sustainability of current systems and make necessary changes that would ensure their sustainability;

2. Reorganize health systems and service delivery infrastructure to meet the emerging needs of older persons, including the special needs of older women;

3. Establish and support mechanisms for self-reliance of older persons through community involvement; provide appropriate support to families for elderly care;

4. Encourage and facilitate the participation of older persons in productive activity through continuous learning and, where possible, by increasing the age limit for retirement;

5. Encourage healthy lifestyles among the young through appropriate health education;

6. Promote the participation of the private sector and non-governmental organizations (NGOs) in old-age care, including health care and in setting up community-based self-help schemes;

7. Support research and knowledge-base development, particularly towards benefiting from the potentials of demographic dividend and the accumulation of wealth; and

8. Disseminate knowledge including national experiences widely to planners and policymakers through appropriate modalities. 


\section{International migration}

International migration, particularly labour migration, from and within Asia has increased significantly during recent decades. This is caused by income disparities and uneven opportunities between countries of origin and destination, imbalances in the supply and demand for labour between them, and improvements in communication, transport as well as Governments' and private agencies' increasing engagement in the management of those flows. It was estimated that the total number of migrant workers deployed by selected Asian countries totaled 2.4 million in 2000, which constitutes an increase of 1.4 million from 1990 (Huguet, 2003). This number is likely to have increased significantly since then, and scattered evidence does not indicate return migration of significant magnitude as a result of current downturn in the economies of receiving countries.

The objectives of the ICPD Programme of Action in addressing the multifaceted issues of international migration are broadly to: derive maximum benefit for both sending and receiving countries from these movements; promote the rights of migrants and their families, providing protection and eliminating discrimination; and ensure that those in vulnerable situations, particularly women and girls, are protected from abuse and have access to basic needs and services.

The Plan of Action on Population and Poverty adopted at the Fifth Asian and Pacific Population Conference agreed on the actions contained in the ICPD Programme of Action, yet it called for the regularization of desirable migration (unauthorized migration that is tacitly accepted by destination countries), better utilization of remittances and the promotion of regional cooperation mechanisms to manage the migration flows (ESCAP, 2003).

A review undertaken by ESCAP in 2009 has identified a number of initiatives taken by both sending and receiving countries to regulate migration and to protect migrants and their families. Examples include the establishment of the Ministry of Expatriate Welfare and Overseas Employment in Bangladesh in 2001, the National Agency for Placement and Protection of Indonesian Overseas Workers in 2006, and the Overseas Employment Administration in Thailand in 2006. The Philippine Overseas Employment Administration and the Sri Lanka Bureau of Foreign Employment are other examples. Likewise, a number of receiving countries have also established systems to regulate the flows of migrants. The review has revealed significant increases in cash remittances through formal channels during recent years. For example, the top 10 countries received a total of $\$ 110$ billion in 2006 and $\$ 121$ billion in 2007 which is more than double the volume in 2000 . These remittances constitute more than twice the amount received 
from official development assistance and is nearly two thirds that of foreign direct investment flows. The trend is likely to continue and there is no evidence that indicates a decline in remittances since the 2008 global financial meltdown. The nature and direction of the impact of remittances for families, communities and for the receiving countries is debated but in most countries remittances have acted as a safety valve that has mitigated high levels of youth unemployment and provided the finance for improving the health and education of family members. At the national level remittances have proved to be a major source of foreign exchange for many countries.

The review also highlighted the adoption of a number of regional and bilateral agreements to coordinate and manage the flow of migrants and to provide protection for them and their families. The review noted that most Asian countries have not ratified international conventions on labour migration that call for the protection of migrant rights, noting also that only a few countries have ratified protocols relating to refugees, as well as smuggling and trafficking. Countries have been more willing to reach agreements on smuggling and trafficking than on labour migration and the protection of migrant rights. Moreover, as noted above, countries have been more forthcoming in forging subregional and bilateral agreements than on ratifying international conventions and protocols.

There have also been improvements in data and research on the economic and social impact of international migration in response to calls made at various Asian regional and subregional forums (for more details see Huguet, 2009).

As discussed earlier, international migration also plays a significant role in both the population dynamics and the economies of many Pacific island countries-mostly in Micronesia and in Polynesia. All Polynesian developing countries have net outward migration, as do four out of five Micronesian countries. Migration streams to and from the Pacific are many and varied as to their countries of origin, destinations, migrants' skill composition, degree of permanence, and gender balance. Some countries have open access to New Zealand and some island citizens can move to and from this country without restriction. In others, migration is controlled by the receiving countries (mostly Australia, New Zealand and the United States of America). Other than Fiji, the countries of Melanesia do not have easy access to international migration and migration plays a negligible role either in their population dynamics or in their economies. It is clear that the economic function of international migration is to transfer labour from a location in which it cannot be absorbed into the labour force towards a location where it can-an inevitable result of "globalization". 
International migration from some Pacific countries is therefore vulnerable to the global economic recession, particularly from countries providing semi-skilled or unskilled workers on temporary labour contracts. A slowdown in recruitment of those occupations is likely to increase the incidence of hardship in the Pacific - especially in the more remote islands that have few other opportunities for wage work. If world economic growth returns to previous levels, the downturn in migration may prove to be temporary. Efforts to design bilateral agreements on unskilled labour mobility between Pacific countries and Australia and New Zealand that would enhance economic growth in island economies are still in early stages (World Bank, 2006).

International migration in Asia and the Pacific will continue to increase in volume and complexity in the coming decades, even if inter-country disparities in labour supply and demand as well as incomes that propel migration will begin to diminish. The development that is taking place in developing countries will further increase migration flows as it will provide the very resources needed for migration. Improvements in communication and transport as well as the growing pool of migration in destination countries will also contribute to further migration. However, the future would also see skilled migrants moving to today's sending countries as a result of increased opportunities arising in them. Therefore, as indicated earlier, international migration will be an important factor in shaping the demographic, economic and social contours of Asia and the Pacific in the twenty-first century. It is inevitable, therefore, that it is accorded high priority in the national development plans and priorities of Asian and Pacific countries in the future.

\section{Population in planning and poverty reduction strategies}

The ICPD Programme of Action reiterated calls to "integrate population issues into formulation, implementation, monitoring and evaluation of policies and programmes relating to sustainable development" (paragraph 3.16) in line with the Plan of Action adopted during the 1974 and 1984 World Population Conferences. The Programme of Action recognizes that "efforts to slow down population growth, to reduce poverty, to achieve economic progress, to improve environmental protection, and to reduce unsustainable consumption and production patterns are mutually reinforcing" (paragraph 3.14).

Previous reviews have revealed that population issues have been at the centre of development efforts in Asian countries and that countries have taken a number of measures to integrate those issues into national development strategies and 
planning. However, the 10-year review of ICPD implementation revealed that the degree of integration of population issues into development strategies among Asian countries vary in scope and depth because of differing views on the complex relationship between population and sustainable development, competing developmental priorities, and inadequate national capacity and methodologies. The changing national contexts and planning systems adopted during recent decades by many Asian countries have added another dimension of challenges (ESCAP and UNFPA, 2004).

With the adoption of the Millennium Development Goals in 2000, however, efforts to integrate population, reproductive health and gender equity considerations into national development and poverty reduction strategies have gained added importance, as achieving the ICPD objectives is seen as pivotal to the attainment of MDGs, particularly the goal of eradicating extreme poverty. A systematic review of the current status of the integration of population, reproductive health and gender issues into national development plans and poverty reduction strategies is lacking. However, a review of national initiatives, plans and strategy documents indicates that in most countries increased efforts are being made towards this particular goal. Those efforts include, inter alia, preparing position papers, organizing national policy dialogues, and taking active part in discussions leading up to the formulation of national development plans and poverty reduction strategies. These same efforts are helped by the progress made during recent years in the collection of data and development of indicators to monitor progress in MDGs and ICPD goals, as highlighted in the preceding section.

While these accomplishments are impressive, it is uncertain whether they have contributed to an increased allocation of resources and to the scaling-up of initiatives to improve reproductive health, including family planning and sexual health services, in ways that have significantly improved access to these services among the poor. Available evidence points to the contrary. For example, it should be noted that public expenditure for health services remains very low and in most developing countries of Asia stands between 1 and 3 per cent of GDP — most of them spending less than 2 per cent or below (UNFPA, 2009). These are also reflected by the fact that indicators of maternal and child mortality, unmet need for family planning, etc. are much higher among people with lowest levels of income. The inequities between the poor-who still comprise a very large segment of the population in most countries of Asia- and the rich are also seen in access to such basic needs and services as safe water and sanitation. 
Therefore, added efforts are required to improve national capacity in the collection and analysis of data to reflect the inequities and their impact on health and educational outcomes and to improve skills to communicate those findings and their relevance to developmental priorities to high level planners and policy makers. Much effort, therefore, is also needed to convince planners and policy makers to translate the commitments to action by increasing investment in human capital — health and education — and their full utilization in development. It must also be highlighted that investments in education and health, will not only contribute towards ensuring that the basic needs and rights of the poor are met but, given the current demographic scenario that many countries are going through, would add significantly to the growth of GDP, by optimizing the benefits of the "demographic dividend".

During the 1990s, Government-led macroeconomic planning in the Pacific subregion was downplayed in favour of a more free-market approach that emphasized private sector development, the privatization of Government commercial arms, and the deregulation of trade, foreign exchange, transport and communications, and labour markets. Under those arrangements there was very little room for population dynamics to be incorporated into plans. Most Governments adopted short-term (2-3 year) development strategies, which made little or no reference to population trends.

Population policies still have a useful role to play in the region and the ICPD Programme of Action provides an appropriate framework to guide their formulation-fully consistent with human rights. MDG-based planning can benefit from a more comprehensive approach to population that a multi-sector population policy can provide.

\section{Data and research}

The ICPD Programme of Action called on Governments to strengthen their national capacity to carry out sustained and comprehensive programmes on the collection, analysis, dissemination and utilization of population and development data. The Programme of Action also called for sociocultural and economic research as well as policy research on a diverse set of issues to be built into population and development programmes and strategies (chapter XII).

In response to the above and with the emphasis placed on the periodic monitoring of MDGs, most countries in Asia have increased their efforts to collect, process and tabulate data that will yield the required indicators for monitoring 
progress in achieving MDGs and ICPD goals. However, data and research gaps to reflect the inequities in incomes, health and educational outcomes, and access to basic services between different segments of the population-e.g. poor and non-poor, migrant and non-migrants, ethnic minorities and indigenous peoples, and those living in vulnerable conditions - as well as on issues such as international migration and ageing are still wide in most countries.

It may be mentioned in this context that many Asian countries have had a long tradition of collecting data through periodic censuses and special purpose sample surveys. While those provide valuable data base for policy analysis, efforts to analyse the data have fallen short in recent years owing to limited national capacity and declining support for in-depth analysis and research.

Pacific countries have carried out censuses either at five-year or ten-year intervals. Building national capacity in census-taking has been an important priority for countries over the past two decades. In spite of these efforts, dissatisfaction continues to be expressed by development partners regarding the infrequency, poor quality or limited range of statistical indicators - including many population-related indicators (AusAID, 2009).

Demands for statistical data have increased significantly since ICPD but, paradoxically, the post-ICPD period also coincided with a decrease in donor support for censuses and surveys. Many of the indicators required to measure the implementation and results of the ICPD Programme of Action were not available for the base year of 1990 and many are still not available. The advent of MDGs has highlighted the deficiencies in data collection in the Pacific and new efforts are underway by several agencies (including the Australian Agency for International Development (AusAID), the Secretariat of the Pacific Community (SPC), New Zealand International Aid and Development Agency (NZAID), ESCAP, UNFPA and the International Monetary Fund (IMF) to improve statistical capacity in the subregion. Particularly urgent is the building of local capacity to analyse census and survey data to make the data more relevant for public policy formulation. A major advance in data collection occurred when demographic and health surveys (DHSs) were conducted in five Pacific island countries over the period 2006-2008, but more analysis of the results is needed for planning purposes.

The Pacific islands still lack sufficient local expertise in census and survey operations, demographic estimation, analysis and interpretation, while support for training and research on population and development has declined during recent years. 
Efforts to bridge those gaps both for data and research should, therefore, be accorded priority in the national development strategies, and in the agenda of development partners, as called for in the ICPD Programme of Action.

\section{Reproductive health and reproductive rights}

\section{Reproductive health and rights in ICPD and ICPD +5 review}

While underscoring the integral and mutually reinforcing linkages between population and development, ICPD made a significant departure from the earlier World Population Conferences in calling on countries to shift their population policies and programmes away from their focus on numbers to a focus on improving the lives of individuals. Principle 8 of the Programme of Action states that "all couples and individuals have the basic right to decide freely and responsibly the number and spacing of their children and to have the information, education and means to do so". In this regard, the ICPD Programme of Action calls upon countries to "... strive to make accessible through primary health care system, reproductive health to all individuals of appropriate ages as soon as possible and no later than the year 2015".

The 10-year review has indicated that most countries in Asia and the Pacific have taken one or more steps to promote reproductive rights. The report of the review states that "even in a favourable policy and programme environment, countries in which educational levels of and employment opportunities for women are low and where socio-cultural and religious factors play a pivotal role, progress towards ensuring the reproductive rights of women remains slow", a statement that still remains true today. The report also highlights factors such as provider bias, and their lack of knowledge, understanding and skills as hindering progress towards achieving the delivery of reproductive health including services that meet the informed and voluntarily determined needs of clients.

The 15-year Asia-Pacific review meeting held in Bangkok on 16 and 17 September 2009 took stock of the progress made in implementing the ICPD Programme of Action from a "rights perspective" and confirmed that there are many factors that limit access to the full range of reproductive health services within countries of the region. Available evidence indicates that rights are more often denied to the poor, the marginalized and vulnerable groups, such as migrants, refugees, and internally displaced persons as well as ethnic minorities and indigenous populations in many countries of the region. Similarly, women, adolescents and unmarried young adults in many countries are also often deprived 
of their rights, including reproductive rights, despite significant efforts made during the past 15 years.

However, countries in Asia and the Pacific have made progress in achieving the specific objectives and goals with regard to selected components of reproductive health during the past years, yet, as discussed below, major challenges still remain.

\section{Safe motherhood and maternal health}

Data given in the tables $1 \mathrm{a}$ and $1 \mathrm{~b}$ show that the proportion of births attended by skilled staff is nearly universal in the countries of East Asia, in Malaysia and Thailand in South-East Asia, and in the Islamic Republic of Iran and Sri Lanka in West and South Asia, respectively. Most other countries, with the exception of a few, are a long way off to ensure that all births are attended by skilled staffwhich is a manifestation of inadequate infrastructure and shortages of skilled birth attendants.

In the Pacific islands, several countries have had universal coverage for some time and all but two countries have already achieved the ICPD target of 90 per cent attendance at birth by skilled personnel by 2015 (see table 1c). Papua New Guinea is the country least likely to achieve this target.

Access to and utilization of prenatal care, as measured by women aged 15-49 years having had four or more prenatal visits during pregnancy was only 36 per cent in South Asia during 2003-2008, and it changed very little since 1990, according to the MDG report of 2009. (United Nations, 2009). For South-East Asia it is much higher and averages about 74 per cent. Data on this indicator are scarce in the Pacific islands but the proportion of all women (15-49 years) attended four or more times during pregnancy ranges from 55 to 88 per cent.

Partly as a result of the above, the goal of reducing maternal mortality ratios (MMR) by three quarters between 1990 and 2015 will not be achieved by many of countries in Asia and some in the Pacific (ADB, 2009). According to the MDG report of 2009 (United Nations, 2009), the MMR for South Asia remains highest in Asia. At 490 maternal deaths per 100,000 live births, the region has recorded only a modest decline of 20 per cent from the 1990 level of 620 . According to the report, South-East Asia ranks second in Asia with an average MMR of 300, which represents a decline of one third from the 1990 level of 450. Western Asia ranks third and has an estimated MMR of 160, down from 190 in 1990. By contrast, East Asia has the lowest MMR: 50, down from 95 in 1990. 
The maternal mortality ratio is perhaps the most difficult health indicator to measure accurately and estimates vary considerably. However, available estimates suggest that the disparities in MMR among and within countries are very high and reflect the high and persistent inequities in access to and quality of basic services, including health services, among the countries and population groups within them. Countries with very high to high MMR in Asia are: Afghanistan $(1,800)$, Bangladesh (570), Bhutan (440), India (450), Nepal (830) and Pakistan (320) in South Asia; Cambodia (540), Indonesia (420), the Lao People's Democratic Republic (660), the Philippines (230), Timor-Leste (380) and Viet Nam (150) in South-East Asia; and the Democratic People's Republic of Korea (370) in East Asia (see tables 1a and 1b).

In the Pacific, most countries of Polynesia and Micronesia, as well as Fiji, have brought maternal deaths to a low level. In Papua New Guinea, the Solomon Islands, the Federated States of Micronesia and Kiribati, however, the situation is quite different (see table 1c). The last recorded MMR in Papua New Guinea (referring to 1994) was 733. Although reliable statistics are unavailable, health authorities and experts believe that this ratio has not improved over the past decade. Accordingly, the MDG target of a 75 per cent decline in MMR by 2015 will not be achieved in Papua New Guinea. The Solomon Islands has made more progress; its current MMR is about 100 - a decline of 70 per cent since the 1990-1994 period.

It is estimated that worldwide more than half a million women die each year giving birth, of which 44 per cent occur in the Asian and Pacific region. The major causes of maternal deaths in Asia include haemorrhage, eclampsia, obstructed labour, sepsis and abortion. Indirect causes include anaemia, jaundice and heart problems. Violence against women also contributes to maternal deaths. Most of those deaths are preventable through proven and cost-effective interventions, but poverty and remoteness are major impediments to obtaining services for many women.

Recent literature points to three primary factors that contribute to high maternal mortality. Those are called the "three delays": (a) delay in making the decision to seek medical help for an obstetric emergency (due to cost), (b) delay in reaching facility (due to distance); and (c) delay in receiving adequate care owing to shortage of skilled staff.

While those delays due to shortages of skilled staff, difficulty in accessing emergency obstetric care and cost considerations retard progress in reducing MMR and improving maternal health, high unmet need for family planning, unplanned 
pregnancies and recourse to unsafe abortions, particularly among adolescents and young women, also contribute to high maternal mortality in a number of Asian and Pacific countries. The 10-year review of ICPD noted that of the countries worldwide that had reported taking a number of steps to reduce MMR, only 15 per cent reported establishing reproductive health/family planning clinics as a strategy (UNFPA, 2004) and in Asia only 7 out of 44 countries reported doing so (ESCAP and UNFPA, 2004) - a situation that is unlikely to have changed since. This reflects a lack of or even a declining importance given by planners and policymakers in many countries of the region to family planning, as it is seen mainly as a means of fertility reduction and not as a cost-effective strategy to improve maternal and child health.

Unsafe abortion is a major public health concern in many Asian countries and account for an estimated 12 per cent of all maternal deaths in Asia. The incidence of unsafe abortion is high in countries where unmet need for family planning is high, where abortion is illegal and quality of care is poor (ESCAP and UNFPA, 2004; see also Karim, 2009). Abortion is illegal in all developing Pacific countries except in situations where the life of the mother is at risk. However, deaths as a result of complications arising from illegal abortions are not unknown in the subregion. Where family planning access is poor, women seek abortions whether they are legal or not (Karim, 2009).

Efforts to get pregnant women at risk of complications to hospitals during emergencies through incentives and support did not always contribute to preventing maternal deaths as women were often discharged soon after delivery due to insufficient facilities at the hospital, and in some cases died soon after owing to complications that could have been prevented if they had not been discharged. As a consequence, maternal mortality during the post-natal period is on the increase among women who received emergency care at delivery. In addition, lack of basic services such as clean water and sanitation facilities, together with poor nutrition, hold back progress in improving maternal health and reducing maternal mortality.

Furthermore, the Executive Secretary of ESCAP, Dr. Noeleen Heyzer points out that "social exclusion, gender inequality, poverty, and violence all act as barriers to women trying to access health services even when they are available" (Heyzer, 2009).

It should also be noted that inadequate care during pregnancy and delivery will have adverse impacts on women's health, and that women who become pregnant during adolescence and women who are malnourished will be at greater risk of prolonged ill health, if not death, due to conditions such as obstetric fistula. 
Inadequate funding for public health is a major factor holding back progress. In most Asian and some Pacific countries, public health expenditure as a percentage of GDP is very low. Shortfalls in donor support for maternal health and family planning and inefficiencies in the utilization of available resources only compound the problem.

Improving maternal health and reducing maternal mortality will, therefore, remain one of the most daunting challenges in the Asian and Pacific region and calls for the following interrelated strategies:

1. Expand access to basic health services, safe water and improved sanitation;

2. Expand access to and improved choice of family planning methods, and make abortion safe where it is legal;

3. Improve prenatal care coverage and identify high-risk pregnancies;

4. Train skilled attendants and improve infrastructure for emergency obstetric care;

5. Reduce the three delays: delay in decision to seek care, delay in transport and delay in providing appropriate care during and after delivery;

6. Target programmes to benefit the poor, socially excluded, marginalized and the vulnerable;

7. Address gender inequality and advocate for the rights of women to safe motherhood and family planning; and

8. Advocate for increased allocation of resources for health and its efficient utilization.

\section{Family planning}

One of the objectives of the ICPD Programme of Action is "to help couples and individuals meet their reproductive goals in a framework that promotes optimum health, responsibility and family well-being, and respect the dignity of all persons and their right to choose the number, spacing and timing of the birth of their children" (paragraph 7.14a). In this regard the Programme of Action calls on countries to "...take steps to meet the family planning needs of their populations as soon as possible, and should in all cases by the year 2015, seek to provide universal access to a full range of safe and reliable family planning methods and related reproductive health services which are not against the law" (paragraph 7.16). 
These calls marked an important shift away from a "target centred" approach to a "needs-based, client-centered" approach that, for the first time, recognized the rights of couples and individuals to decide freely and responsibly the number and spacing of their children and to have the information and means to do so. It explicitly stated that "demographic goals should not be imposed on family planning providers in the form of targets and quotas for the recruitment of clients", a practice that was previously followed in many Asian countries.

The 10-year review reported that "since ICPD in 1994, all the countries that had pursued policies involving the setting of targets or quotas and incentives to meet fertility goals have abandoned them in spite of the reservations expressed by some that this, together with the integration of family planning with broader reproductive health care, might have a negative impact on the acceptance of family planning and on the contraceptive prevalence rate" (ESCAP and UNFPA, 2004). A review conducted as part of the Fifth Asian and Pacific Population Conference has also shown that "the integration of family planning into reproductive health programmes that provide men and women with choice in planning their reproductive lives, while still incomplete, has not led to reversals in fertility decline" (Guest, 2003 cited in ESCAP and UNFPA, 2004).

Evidence available from recent surveys indicate that though there has been no reversal in fertility decline, in a number of countries the decline in fertility rates has halted or its rate of decline has slowed. Moreover, even as contraceptive prevalence has increased, the unmet need for family planning remains high in a number of countries in Asia and the Pacific and is 20 per cent or more in Afghanistan, Cambodia, the Democratic People's Republic of Korea, the Lao People's Democratic Republic, Malaysia, Nepal, Pakistan and Papua New Guinea (see tables 1a and 1c). In a few Asian and Pacific countries, the desired number of children remains high while in a number of others there is a wide gap between the desired and the actual number of children. Moreover, there is significant variation among countries with regard to their contraceptive prevalence rates (CPRs) and in the availability and use of modern methods - as can be seen from the tables. Countries with high CPRs (more than 60 per cent) are China, the Democratic People's Republic of Korea, the Islamic Republic of Iran, Mongolia, Sri Lanka, Thailand and Viet Nam. Countries with especially low CPRs include Afghanistan (10), Timor-Leste (10), and Pakistan (28). Likewise, there are variations among countries with regard to the choice of methods made available to clients.

The very slow rate of improvement in CPRs in some countries has been an issue of concern in recent years because, if they persist, they will result in the 
persistence of rapid rates of population growth which is seen by many as an obstacle to poverty reduction and as contributing to the deterioration of the environment and climate change. Moreover, rapid population growth is also seen as hindering efforts to achieve other reproductive health goals, including reduction in MMR and child mortality, as well as stemming the spread of HIV/AIDS, as discussed in the following section.

In view of the above, there has been a growing chorus of calls to reposition and revitalize family planning as part of the development agenda in the coming years. For example, the Declaration adopted at the 15-year review forum in Bangkok on 16 and 17 September 2009 called for enhanced "political commitment to reposition and revitalize family planning as a development agenda for achieving reproductive health outcome as well as broader poverty reduction goals" (ESCAP, 2009c).

The latest MDG report (United Nations, 2009) notes that "funding gaps are conspicuous for programmes needed to meet MDG 5, the goal towards which least progress has been made". The report concludes that "the strengthening and expansion of family planning programmes can make a major contribution to improvements in maternal and child health, but require adequate funding and access to supplies. Yet, since the mid 1990's, most developing countries have experienced a major reduction of donor funding for family planning on a per woman basis".

One of the major priorities in moving the ICPD agenda forward, therefore, is to "reposition" family planning as central to the development agenda by allocating adequate resources for ensuring the supply and availability of family planning commodities and making it accessible and affordable to those for whom access is presently severely limited.

\section{HIV/AIDS}

One of the objectives of the ICPD Programme of Action is to "prevent, reduce the incidence of, and provide treatment for, sexually transmitted diseases, including HIV/AIDS, and the complications of sexually transmitted diseases such as infertility, with special attention to girls and women" (paragraph 7.29). The Key Actions adopted at the five-year review called on Governments to "ensure the prevention of and services for sexually transmitted diseases and HIV/AIDS are an integral component of reproductive and sexual health programmes at the primary health-care level (Key Actions, paragraph 68). The United Nations Millennium 
Declaration calls on Governments to halt by 2015 and begin to reverse the incidence of HIV/AIDS.

At the regional level, the Fifth Asian and Pacific Population Conference, held in Bangkok in 2002 reviewed the HIV/AIDS situation in Asia and the Pacific and called on Governments and all development partners to: "Establish (a) national prevention programmes, recognizing and addressing the factors leading to the spread of the epidemic, reducing HIV incidence for those identifiable populations with high or increasing HIV infection or indicated through public health information as at the highest risk of infection, (b) information and education programmes aimed at risk-taking behaviour and encouraging responsible sexual behaviour and expanded access to essential commodities..." (ESCAP, 2003, p. 28).

The 10-year review found that most Asian countries have taken steps to stem the spread of HIV/AIDS but noted that in most instances prevention programmes reach only a small proportion of those who are infected or could potentially be exposed to HIV/AIDS infection. The review also noted that accessibility and affordability of testing for HIV and subsequent treatment is limited in most countries. It also highlighted the social and cultural constraints that inhibit the promotion of safe-sex practices particularly among adolescents and unmarried youth, who are most vulnerable. The review has cited Cambodia and Thailand as leading examples to contain and reverse the spread of HIV through effective programmes to promote awareness and condom use (ESCAP and UNFPA, 2004).

The report of the Commission on AIDS in Asia, published in 2008 (see Commission on AIDS in Asia, 2008 for more details), is the most recent and comprehensive survey of the situation of HIV/AIDS in Asia. According to the report, though HIV prevalence rates in Asia are low the numbers infected are high, and it is estimated that the number of people living with HIV was about 4.9 million (estimates range from 3.7 to 6.7 million) in 2007 . It is estimated that 440,000 people are newly infected each year with HIV in Asia and that about 300,000 succumbed to the disease in 2007.

The report notes that the incidence and prevalence of HIV and AIDS vary considerably among the Asian countries. For example, HIV prevalence among men and women aged 15-49 years are highest in Cambodia (1.2 and 0.5 per cent), the Democratic People's Republic of Korea (1.1 and 1.6 per cent), Papua New Guinea (1.8 and 1.2 per cent, respectively) and Thailand (1.7 and 1.2 per cent). It is also high in India ( 0.4 and 0.3 per cent), Malaysia ( 0.8 and 0.3 per cent), Myanmar ( 0.8 and 0.6 per cent), Nepal ( 0.7 and 0.3 per cent) and Viet Nam 
(0.8 and 0.3 per cent). In Indonesia, the Islamic Republic of Iran and the Lao People's Democratic Republic, the rates are 0.3 and 0.1 per cent, respectively, for males and females. In all other countries the rates are about 0.1 per cent for both sexes. It is also evident that in Asia, HIV prevalence rates are much higher among males than among females (UNFPA, 2008a). In the Pacific, HIV prevalence rates are gradually becoming more equal between males and females.

According to the report of the Commission on AIDS in Asia, transmission of HIV in Asia is mainly due to unprotected paid sex, sharing of contaminated needles and unprotected sex between men. The report makes the following conclusions with regard to the future of the pandemic in Asia:

- Men who buy sex, most of whom are from "mainstream society", are the single most driving force in Asia's HIV epidemics and constitute the largest infected group. Because most men who buy sex are married or will get married, significant numbers of ostensibly "low-risk" women who only have sex with their husbands are exposed to HIV. Effective means of preventing HIV infections in the female partners (wives or girlfriends) of these men have yet to be developed in Asia, but are clearly essential.

- Because relatively few women in Asia have sex with more than one partner, the chain of infection tends to end with their wives or girlfriends, though infected mothers might transmit the virus to their unborn or new born infants.

- Hence HIV epidemics in Asia is unlikely to sustain in the general population, independently of commercial sex, drug injecting and sex between men.

- Hence, prevention efforts that drastically reduce HIV transmission among and between these most-at-risk populations will bring the epidemics under control.

The report further highlights that stigma and discrimination undermine Asia's response to the epidemic and prevents people from accessing services such as counselling and testing.

Thus, in Asia, HIV transmission is largely driven by male behaviour and the conventional wisdom of marriage, instead of protecting women, has become a risk factor for women in contracting HIV. Therefore, preventing men from getting infected through targeted efforts at most-at-risk groups is one way to contain the spread of AIDS. However, it ignores the fundamental right of women to protect 
themselves and their children from contracting HIV. In addition, gender-based violence, which is widely prevalent in many Asian countries, is reported to increase the risk of HIV among women by 50 per cent. Empowering women should therefore also be a priority strategy to contain the spread of HIV/AIDS (PPD, 2008).

Furthermore, preventing men from getting infected though targeted at most-at-risk groups will not protect unsuspecting wives and girlfriends from getting infected with HIV from an unfaithful partner. In this regard, the Commission calls for a strategy to be developed to prevent infections among these women and girls who would not contract HIV except from their husbands or boyfriends.

The Commission notes that "despite the relatively low numbers of people in Asia who currently need antiretroviral therapy (ART), only one in four (26 per cent) people are receiving it" (Commission on AIDS in Asia, 2008).

In the Pacific islands, surveillance remains insufficient to determine the precise scale and pattern of HIV infection in all countries. It is clear, however, that Papua New Guinea is the most affected country with HIV prevalence estimated at 1.6 per cent of the adult population in 2007 (National AIDS Council Secretariat, 2007; Government of Papua New Guinea, 2009). Elsewhere in the Pacific, HIV prevalence in the adult population remains low. Although the annual rate of HIV reporting shows an upward trend from the mid-1980s, the number of reported cases per year in Polynesia has remained relatively constant since 1996.

The predominant mode of HIV transmission in the Pacific is heterosexual (50 per cent) followed by male-to-male sex ( 29 per cent) and injecting drug use (6 per cent). As the injection of drugs is rare in the Pacific, this mode of transmission probably occurred outside the region, but was reported locally. Risk factors vary from country to country.

An underlying condition that is conducive to the heterosexual transmission of the HIV virus in the Pacific is the high prevalence rates of other sexually transmitted infections (STIs). Recent clinical surveys (WHO, 2006) found high rates of chlamydia (up to 41 per cent) and gonorrhoea (up to 1.7 per cent) in women under 25 years of age. Expert opinion is that little improvement in these prevalence rates is evident in recent years. Contributing to this pessimistic outlook is the low level of condom use and poor access to treatment-especially for adolescents. Although condom use has been increasing, the use of condoms in "high risk" sex remains below 20 per cent in the countries surveyed. Adolescents also find it 
difficult to obtain non-judgemental treatment in the Island countries where health services are mostly provided by Governments. NGOs have had more success in reaching young people.

Family planning programmes can be an effective way to reach out to women at risk of HIV infection with information and services, including counselling, on HIV transmission and prevention. The call for providing integrated reproductive health services, including family planning, in the context of primary health care made at ICPD is important because, among other things, it would protect the confidentiality of women seeking information and services on HIV/AIDS and avoid their stigmatization. It would also reduce the risk of mother-to-child transmission of HIV. Linking HIV/AIDS and safe motherhood/family planning services would provide synergy and contribute to the attainment of the ICPD goals and the Millennium Development Goals.

The report of the Commission on AIDS in Asia recommends that "reproductive health services should be used as an entry point to increase women's access to HIV prevention, testing and referral services". Family planning is a central component of reproductive health and family planning programmes have reached those women successfully in all countries of Asia. Therefore, efforts to integrate the provision of HIV/AIDS and family planning services should be a priority strategy, as it would give married women a chance to protect themselves from contracting HIV.

This is in line with suggestions made elsewhere; for example, in 2005, a joint initiative by the International Planned Parenthood Federation (IPPF), UNFPA, the World Health Organization (WHO) and the Joint United Nations Programme on HIV/AIDS (UNAIDS) produced a framework for such priority linkages as a guide for countries to effectively link and integrate sexual and reproductive health and HIV. The review showed that linking sexual and reproductive health and HIV was beneficial and feasible, especially in family planning and HIV testing centres (for more details on this linkage, see Zaman and Masnin in this same issue of the Asia-Pacific Population Journal.) Cost-effective studies suggested net savings when HIV and prevention of sexually transmitted infections are integrated into maternal and child health services (Karim, 2009).

In spite of the obvious benefits and synergies, efforts to integrate components of reproductive health services, even on a limited scale between HIV/AIDS and safe motherhood/family planning services, have had limited success and face severe constraints in many Asian countries, as discussed in the ICPD 10-year review report 
(ESCAP and UNFPA, 2004). Yet, advocating for the integration of HIV/AIDS and family planning should be a priority during the coming years.

Meeting the needs of adolescents and young people, particularly girls, for information and services, including counselling on sexually transmitted diseases and HIV/AIDS is a challenge for Asian countries because in most countries, conventional family planning services are accessible only to married women and men. Progress and challenges in meeting the specific needs of this age group are discussed in the next section.

\section{Adolescent reproductive health}

The ICPD Programme of Action is the first international agreement to explicitly address the reproductive health needs of adolescents. Despite an ever increasing number of adolescents in most Asian countries and evolving behavioural patterns among them, including in matters related to sex, the issue was never before placed on an international agenda. The main objective, as stated in the Programme of Action, is "To address adolescent sexual and reproductive health issues, including unwanted pregnancy, unsafe abortion, and sexually transmitted diseases, including HIV/AIDS, through the promotion of responsible and healthy reproductive and sexual behaviour, including voluntary abstinence, and the provision of appropriate services and counselling specifically suited for that age group" (ICPD Programme of Action, paragraph 7.44a).

The ICPD Programme of Action called on Governments "to meet the needs of adolescents and to establish appropriate programmes to respond to those needs". The Key Actions adopted during the five-year review further called on Governments "to protect and promote the rights of adolescents to the enjoyment of highest attainable standards of health" and towards this end, "provide appropriate, specific, user-friendly and accessible services to address effectively their sexual and reproductive health needs..."

A regional assessment carried out in preparation for the Fifth Asian and Pacific Population Conference in 2002 noted the progress accomplished by countries in Asia (Jejeebhoy, 2002). While noting that Asian adolescents are not a homogenous group and live in diverse social and cultural contexts, the assessment called for interventions that are flexible and responsive to these disparate needs. It also noted: (a) sexual and reproductive health needs of adolescents are highlighted in national agendas of Asian countries; (b) young people's knowledge and awareness about reproductive health is increasing but remain superficial; and 
(c) lack of communication with parents and other trusted adults keep young people ill informed.

The 10-year review undertaken in 2004 (ESCAP and UNFPA, 2004) indicated that countries have taken a number of measures that include, among others: (a) introduction of out-of-school youth programmes; (b) training of teachers on adolescent health issues; and (c) peer education. It was clear during the review that while progress was made in a number of countries it was limited to the formulation of policies/strategies and/or the provision of education, information and counselling. Reproductive health services were not available in most countries to adolescents and unmarried young people. In countries with very low age at marriage, social factors limited access to reproductive health/family planning services to adolescents and young people, even if they were married. The important role played by NGOs in a number of countries in Asia in initiating innovative interventions to meet the needs of adolescents was also highlighted during the review.

One of the major initiatives undertaken in seven countries of Asia (Bangladesh, Cambodia, the Lao People's Democratic Republic, Nepal, Pakistan, Sri Lanka and Viet Nam) is the Reproductive Health Initiative for Youth in Asia (RHIYA) project - a collaborative effort by the European Union and UNFPA. The project, implemented with the active involvement and participation of many national NGOs, piloted innovative approaches to reach adolescents, in different settings, with information, counselling and services on reproductive and sexual health.

In addition, efforts to create an enabling environment through supportive policies and to reach adolescents, in diverse settings, with information and counselling have continued in most countries of Asia (Karim, 2009).

Many countries in the region have also conducted special surveys on sexual behaviour and sexual and reproductive health issues among adolescents and youth or have included such information on other surveys such as the demographic and health surveys. Those are providing valuable information to guide policies and programmes.

The ICPD Programme of Action stresses the need to "substantially reduce all adolescent pregnancies" (paragraph 7.45). The teenage fertility rate (births per 1,000 women aged 15-19) is normally used to measure adolescent fertility. As can be seen from the tables $1 \mathrm{a}$ and $1 \mathrm{c}$, teenage fertility rates remain high in many 
countries of Asia and the Pacific. It is very high in Bangladesh (125 per 1,000 women), Nepal (115) and Afghanistan (113) but is the lowest in China (8) and the Democratic People's Republic of Korea (1). Teenage fertility is approaching low levels in Malaysia (13), Myanmar (16), Viet Nam (18), the Islamic Republic of Iran (20) and Sri Lanka (25). It should be noted that in most Asian countries teenage fertility mostly occurs within marriage, and as was indicated earlier, in most of these countries, social and cultural factors limit adolescents' access to reproductive health, including family planning services. This exposes them to early pregnancies that pose high risk to themselves, the unborn or the newborn. In addition, increases in unprotected sex among unmarried adolescents increase the risk of unwanted pregnancies leading to unsafe abortion and complications or death arising from them. Available evidence indicates that a significant proportion of maternal deaths in Asia occur among adolescents and young women and that an important cause of these deaths is unsafe abortion.

Teenage fertility in the Pacific islands has historically been high relative to more developed regions but since the 1990s several island countries have experienced declines of 20 to 40 per cent. In Polynesia and Fiji, teenage fertility is now below the average for the South-East Asian region, but some countries and areas of Melanesia and Micronesia have displayed persistently high rates in the range of 67-95 births per 1,000. In the Marshall Islands, the 2007 DHS found that over one quarter of girls aged 15-19 were either pregnant or had already given birth. Unlike the situation in Asia, adolescent pregnancy in the Pacific occurs mainly among unmarried girls. The main consequence is disrupted schooling and reduced life prospects, while unsafe abortion and maternal death can also occur.

Thus, although there have been major national and regional efforts by Governments, NGOs and other development partners during the past 15 years to improve access to reproductive health services to adolescents, those efforts, at best, have reached only a small proportion of the population in this subgroup whose numbers are now at a peak in Asia and much of the Pacific. Significant hurdles for meeting the reproductive health needs of adolescents and young people include, among other factors, social and cultural norms, gender inequality, attitudes of parents, teachers and service providers, and low levels of enrolment as well as the gender gap in secondary schools that still persist in many countries of Asia. Addressing those constraints, therefore, must constitute a high priority in future years. 


\section{Access, quality and integration of services}

\section{Access to reproductive health-care}

The ICPD Programme of Action calls upon all countries to "strive to make accessible through the primary health-care system, reproductive health to all individuals of appropriate ages as soon as possible but no later than the year 2015" (paragraph 7.6). Key Actions adopted during the five-year review in 1999 is more specific, calling on Governments to "strive to ensure that by 2015 all primary health-care and family planning facilities are able to provide, directly or through referral, the widest achievable range of safe and effective family planning and contraceptive methods; essential obstetric care; prevention and management of reproductive tract infections, including sexually transmitted diseases; and barrier methods such as male and female condoms and microbicides if available, to prevent infection. By 2005, 60 per cent of such facilities should be able to offer this range of services, and by 2010, 80 per cent of them should be able to offer such services" (paragraph 53).

The inadequacies of health information systems in Asia and the Pacific make it difficult to assess the extent to which primary health-care and family planning facilities across the region are able to provide the range of reproductive health, including family planning, services envisioned by the ICPD Programme of Action and the ICPD +5 review. However, realization of this objective is contingent upon the attainment of the goal of universal access to basic health services through a primary health-care approach, as called for in the Declaration of Alma-Ata adopted at the International Conference on Primary Health Care in 1978, in Almaty (formerly Alma-Ata). While the majority of Asian and Pacific countries have achieved this goal, there are a number of countries in Asia and the Pacific (for example, Afghanistan, Cambodia, India, Indonesia, the Lao People's Democratic Republic, Pakistan, Papua New Guinea and the Philippines) where large segments of the population do not have access to basic health services. Lack of access to basic health services, therefore, is a major bottleneck in these countries towards improved access to the full range of reproductive health services at the primary health-care level or through referrals to higher levels of care.

Available information indicates that more than 95 per cent of the service delivery points (SDP) in most countries of Asia and the Pacific provide three or more contraceptives. However Afghanistan (83), Bangladesh (70), India (90+), Pakistan (70), Kiribati (68) and Samoa (78) are countries in which a significant proportion of SDPs do not provide three or more contraceptives (UNFPA, 2008b). 
Though information on the specific type of contraceptive available in an SDP is not available, it is likely that the three methods dispensed at most points will include pills, male condoms and injectable (Depo Provera). Availability of other methods (e.g., intrauterine device (IUD), Norplant and sterilization, which require the service of a skilled staff member) will be limited to secondary and tertiary level facilities, and may be accessed through referral. Emergency contraception and female condoms are unlikely to be available in most SDPs, and this would limit choice.

The ICPD at 10 report for Asia and the Pacific (ESCAP and UNFPA, 2004) highlighted the steps taken by a number of countries to improve access to a range of reproductive health, including family planning services through outreach programmes, community-based distribution of contraceptives and through NGO outlets.

In recent years, emphasis has been placed on reviewing service gaps and barriers to address the unmet needs for reproductive health and family planning, and to address needs of marginalized groups, those with higher vulnerability and populations living in crisis and post-crisis situations.

Though Governments are the main providers of health, including reproductive health, in most Asian countries NGOs and the private sector play a complementary role in improving access to reproductive health services and commodities, including contraceptives. In a number of countries, NGOs, by and large, address the needs of poor and hard-to-reach segments, while the private sector largely caters to the needs of the urban and non-poor segments of the population.

Lack of service delivery point or outpost, lack of inadequate integration of reproductive health services, including family planning, and factors such as poverty, distance, terrain, gender inequality, and cultural norms that limit or constrain access to women, adolescents and young people, retard progress in achieving the goal of universal access to reproductive health in many Asian countries, resulting in the adverse health outcomes discussed in the preceding sections. It should be noted that it is the poor, marginalized and those living in vulnerable conditions that have least access and suffer the most adverse consequences.

Access to supplies and services in the Pacific is determined by the proximity of the SDP to the population and the likelihood that the SDP will have the required commodity in stock and staff on hand qualified and willing to dispense it. In many rural areas access in this sense remains poor. Second, the prospective client must 
be seen as eligible to receive the service in the view of the service provider. In some countries, service providers demand parental approval before dispensing contraceptives to unmarried men and women under 20 years of age.

Available evidence in the Pacific suggests that only general hospitals (located in the national capital), or district hospitals in the larger countries, would be able to deliver the full range of reproductive health, including family planning, services. But even in those locations, services may not necessarily include the female condom, which has only recently been introduced in the region. Recent studies suggest that it is not uncommon for hospital-based reproductive health clinics to offer four alternative methods of contraception (pills, injectables, condoms, IUDs) as well as male and female sterilization, but health centres and primary health facilities in rural areas are unlikely to be able to offer such choices.

\section{Quality of reproductive health-care}

If information on access to reproductive health care is limited, as noted in the preceding section, it is less likely that information on quality of care and its various elements is collected, even using sampling methods, in most countries. Key elements of quality of care include client choice of methods, information for and counselling of users, the technical competence of service providers, interpersonal relations between providers and clients, mechanism for follow-up and continuity of care and an appropriate constellation of services.

Based on the information collected through a field inquiry, country reports presented at the Fifth Asian and Pacific Population Conference and the ICPD at 10 report for Asia and the Pacific, it must be concluded that factors such as inadequate skills of service delivery personnel, lack of client orientation in the delivery of services, insufficient mechanisms for follow-up and supervision and the limited choice available to clients impede progress towards high quality reproductive health care. The reports also noted that progress is being made and it cited specific examples of the steps taken by countries to improve quality of care which include, among others, capacity development through training of service providers, establishment of standards of care and protocols, adoption of guidelines for "gender sensitive" care, and strengthening of logistics to ensure supply and availability of reproductive health commodities, including a mix of contraceptives.

In all likelihood, those efforts and other interventions to improve service quality have continued at the national level. However, in most countries and at the regional level insufficient importance is given to the collection and analysis 
of information on quality of care, and this makes it difficult to draw any definitive conclusions on the rate of progress in improving the quality of reproductive health care. Monitoring progress in quality of care is particularly important to assess whether reproductive health, including family planning, information, counselling and services, that are provided in the Asian and Pacific countries respects the rights of individuals and couples, as called for in the ICPD Programme of Action.

\section{Integration of reproductive health services}

As noted earlier in this paper, the ICPD Programme of Action calls upon countries to "...strive to make accessible through primary health care system, reproductive health to all individuals of appropriate ages as soon as possible and no later than the year 2015". The Programme of Action has also identified the major components of reproductive health care. Specifically, the Key Actions adopted at the five-year review has called upon countries to ensure that 60 per cent of primary health-care and family planning facilities offer a wide range of services by 2005 , including family planning, obstetric care, and prevention and treatment of RTIs including STDs and that 80 per cent of SDPs will do so by 2010 .

The ICPD +10 report for Asia and the Pacific noted that countries in the Asian and Pacific region have made efforts to integrate the various components of reproductive health, including family planning, by identifying essential services package of reproductive health services in the respective national contexts. The review report also noted that countries with well-developed health infrastructure and in which family planning services formed part of the health services are moving closer towards fuller integration of services. However, in countries that had vertical programmes for family planning, the move towards integration is proving to be difficult due to a number of factors, and this remains true even today (ESCAP and UNFPA, 2004).

Full integration of services requires management arrangements to facilitate an integrated system of service delivery, including logistics and information support, and the development of human resources. Constraints or obstacles to the integration of the different components of services, which have obvious benefits, are both country- and donor-driven. At the country level they include weak infrastructure, vertical planning, limited community involvement and lack of focus on integration during in-service and pre-service training. Constraints that emerge from donors include misalignment between country and donor priorities, donor competition, and poor harmonization (PPD, 2008). 
Given that integration of major components of reproductive health, safemotherhood, family planning and HIV/AIDS, is cost-effective and has proven benefits to improve health outcomes - including reduced maternal and child mortality and constraining the spread of HIV-efforts to integrate these services should be pursued as a priority through active advocacy at the highest echelons of Government and in the context of health sector reforms.

\section{Reproductive health commodity security}

The ICPD Programme of Action and the Key Actions of ICPD +5 have stressed the need to ensure reliable and adequate supply of a range of reproductive health commodities, including contraceptives. Increased demand arising from the large number of people currently in the reproductive ages in most Asian and Pacific countries is stretching the ability of countries to meet the increasing demand, a situation which is only aggravated by the economic and financial crisis that hit the countries of the region in 1997 and again in 2008.

Ensuring commodity security has different dimensions. Those include, among others, the following: ability to forecast and respond to demand when the need arises; improvements in procurement and logistics management to ensure supply at service delivery points; ensuring availability and affordability for the poor, marginalized and the vulnerable; and ensuring adequate resources for reproductive health commodities, including contraceptives. It also includes that reproductive health commodities, including contraceptives, meet the needs of clients who have their own preference and choice for one or other methods.

Ensuring reproductive health commodity security has been an important concern for national Governments and development partners, as it is a central to the achievement of the ICPD goals and the Millennium Development Goals. Failure to meet the requirements of reproductive health equipment and supplies, including contraceptives, would result in unwanted pregnancies, unsafe abortion and limit the ability to manage the complications arising from them. In significant number of cases these will lead to maternal death. It will also retard efforts to fight the continuing spread of the HIV/AIDS pandemic, particularly among adolescents and young people.

The ICPD at 10 review report for Asia and the Pacific has noted that countries in Asia and the Pacific have taken variety of measures to improve reproductive health commodity security (RHCS). These efforts include: promoting partnerships with NGOs and the private sector in improving access to reproductive health 
commodities, including contraceptives; making improvements in the procurement and distribution of reproductive health commodities and supplies and strengthening logistics management and information systems; securing technical and financial support from international agencies, including donor agencies.

However, the capacity of countries to plan and manage an efficient logistics management information system, and to procure, store and distribute the reproductive health commodities to SDPs in time, and to ensure access to contraceptives for the poor and vulnerable vary among the countries of Asia. Religious and other factors play a role in determining policies on the method mix made available to the clients in some countries.

Assessments of RHCS have been conducted in several Pacific Island countries in recent years, and while some improvements are evident, significant impediments to RHCS remain - even in the more developed countries. Several Pacific countries have also developed strategies to improve RHCS —often within the context of a broader reproductive health strategy. But few countries have made specific allocations for reproductive health $(\mathrm{RH})$ commodities in their national budgets, in spite of ministerial level commitments to do so. All developing Pacific countries remain totally or predominantly dependent on UNFPA and/or other donors to provide reproductive health supplies. UNFPA has recently upgraded its purchasing and distribution system at the regional level, so the countries are well served, but many countries have not complemented this support by improving warehousing and distribution systems at the national level. Despite some progress and high-level political commitment, much remains to be done to ensure that $\mathrm{RH}$ commodities are physically available when and where required.

Challenges facing Pacific islands include maintaining supply under difficult geographic conditions, building the capacity of countries to manage the logistics of medical supplies of all types, including RH commodities, and developing skills of estimating and projecting demand, ordering stock, and maintaining inventories. Maintaining the quality of supplies is a further challenge owing to a combination of climatic conditions and an insecure supply chain that exposes goods to deterioration. 


\section{Gender equality and empowerment of women}

\section{Education}

The ICPD Programme of Action called upon countries to go beyond the achievement of the goal of universal primary education by 2015 and ensure the widest and earliest possible access by girls and women to secondary and higher levels of education, as well as to vocational and technical training (paragraph 4.18).

The Key Actions adopted at ICPD +5 urged all countries to eliminate the gender gap in primary and secondary school attendance by 2005 and to raise primary enrolment to 90 per cent by 2010 (Key Actions, paragraph 34). Similarly, the MDG target is to "eliminate the gender disparity in primary and secondary education, preferably by 2005 and in all levels of education no later than 2015 ".

Regional reviews undertaken for the Fifth Asian and Pacific Population Conference, and as part of the 10-year review of ICPD implementation, have shown marked improvements in enrolment in primary and secondary education and in bridging the gender gap (ESCAP and UNFPA, 2004). The review highlighted specific measures that have been taken by Governments to ensure universal primary education and to bridge the gender gap.

According to recent data (UNFPA, 2008), the gross enrolment ratio (the ratio of pupils of all ages enrolled at primary level to the number of children in primary school ages) at primary level is 100 or more in most Asian countries, which is indicative of progress towards the achievement of universal primary education for both girls and boys, except in Pakistan where female enrolment lags considerably behind at 74 per cent (see table 2a). However, net enrolment figures (ratio of pupils of primary school ages enrolled at primary level to the estimated number of children of primary school ages) for 2005 indicate that in some countries (Lao People's Democratic Republic, Nepal, Pakistan and Papua New Guinea) these are lower for girls than boys, and even among boys the ratios are well below 100 (Osteria, 2009).

Gross enrolment ratios at secondary level, by contrast, are low in most Asian countries and the ratios vary significantly among them. There are also variations among countries with regard to gender gap at secondary level, with some countries having higher ratios among girls than boys (e.g., Malaysia, Mongolia, the Philippines and Thailand) while in many others they are lower among girls (e.g., Cambodia, Lao People's Democratic Republic, and all countries in South and West Asia except Bangladesh and Sri Lanka). 


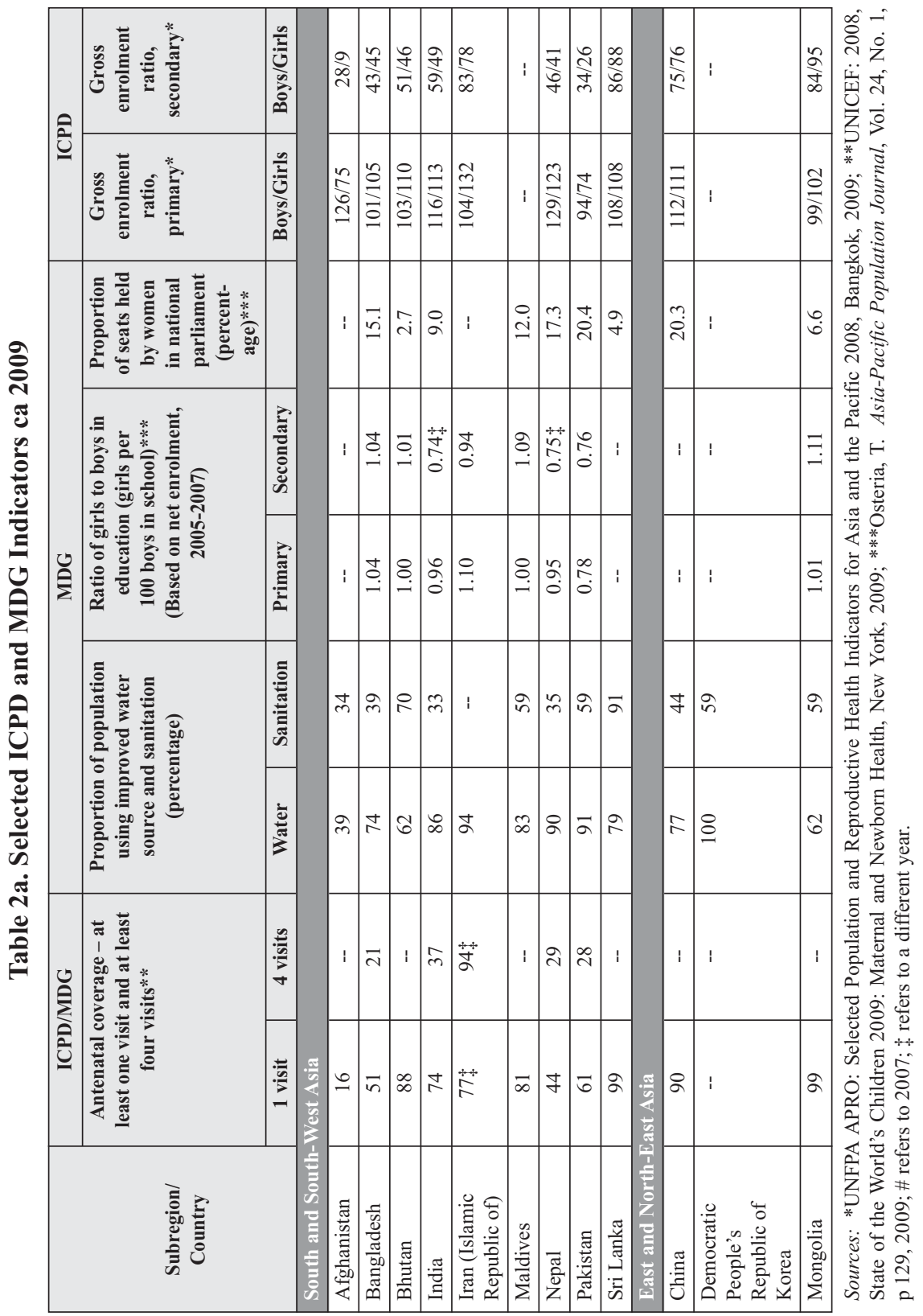




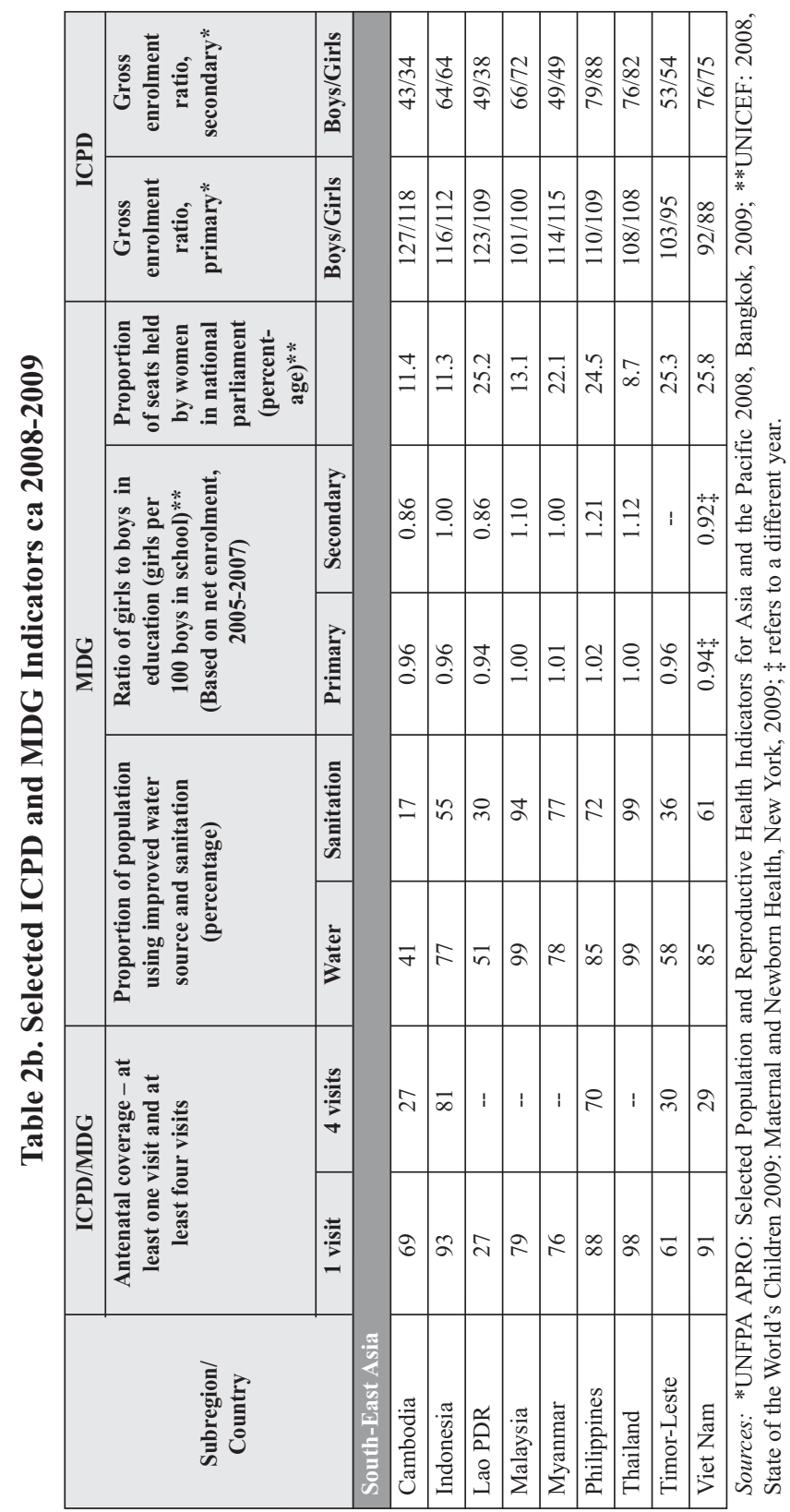




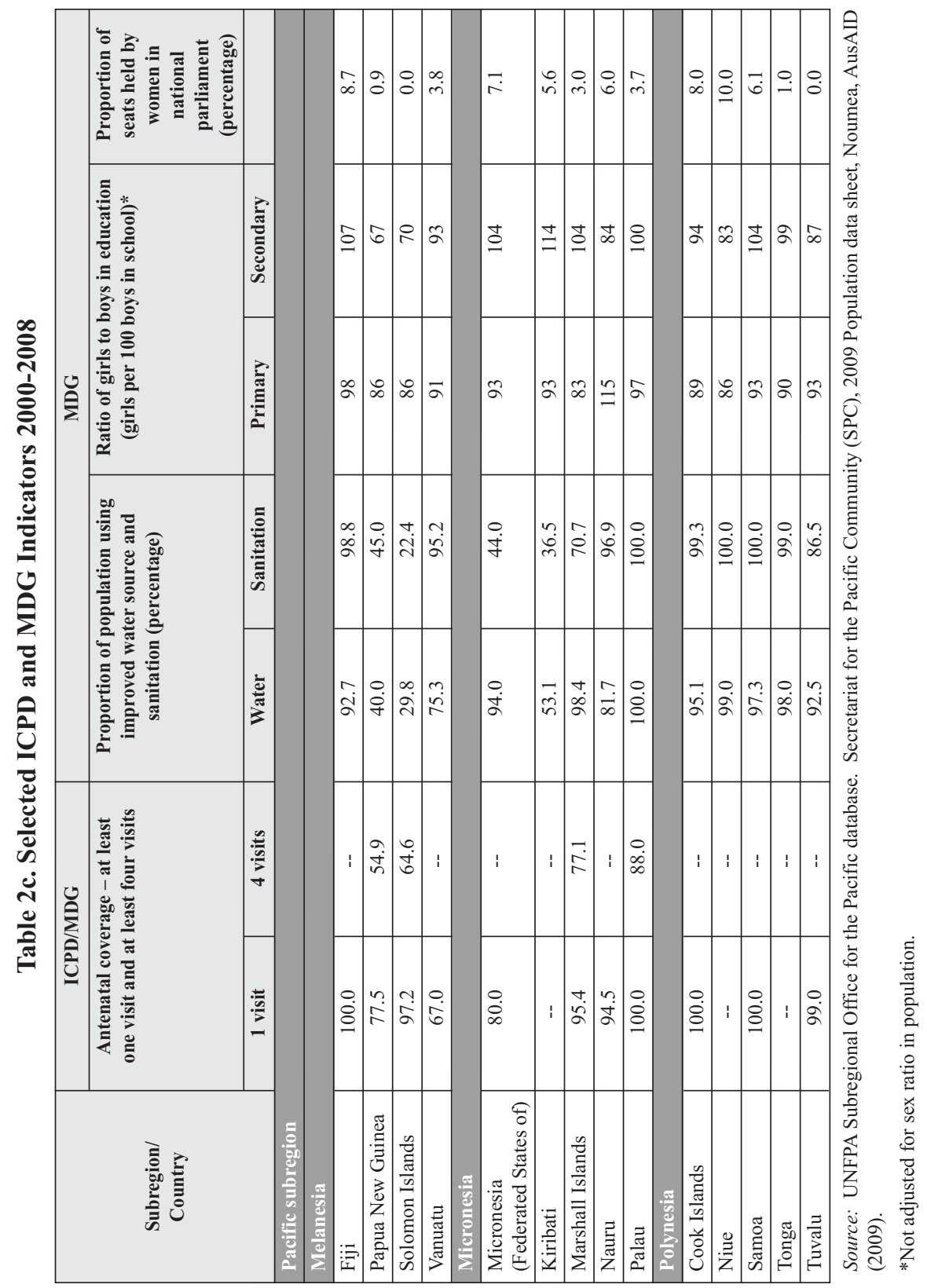


In the Pacific, based on gross enrolment, the gender gap in primary and secondary education is generally small although there are notable exceptions. At primary level, the gap ranges from 0 to 13 per cent, while at secondary the range is wider-from 1 to 24 per cent (in some countries more girls than boys are enrolled in school). The gender gap at the secondary level is greatest in the less-developed Melanesian countries of Papua New Guinea and the Solomon Islands, and smallest in Micronesia and Polynesia. Net primary enrolment is near or above 90 per cent in most Polynesian and Micronesian countries but falls well short of this level in Papua New Guinea and the Solomon Islands.

Gender equality in education is close to being achieved at the primary level across the Pacific subregion but there is some distance to go before the gap is closed at the secondary level (see table 2c). Because much tertiary education takes place outside the region, it is difficult to estimate the gender gap at the tertiary level. However, most Governments and international scholarship providers do strive to maintain a gender balance in the provision of tertiary scholarships.

\section{Employment and wages}

ICPD Programme of Action has urged all countries to adopt "appropriate measures to improve women's ability to earn income beyond traditional occupations, achieve self reliance, and ensure women's equal access to the labour market and social security systems" (paragraph $4.4 \mathrm{~d}$ ).

Large numbers of women are economically active in a number of Asian countries. In a number of countries many of them work for paid employment in the agricultural sector and many others work as unpaid family workers. Many women also work in their own homes producing products for sale in the market.

Patterns of employment among women in Asia have been undergoing significant change as a result of the improved education of girls and in response to growing demand for labour. In addition, the number of migrant women workers from a number of Asian countries, including those who move across countries, have increased significantly during recent years. While these trends have been favourable to the advancement of women and for their empowerment and equality with men, many women face discrimination in wages, career development, etc., and experience work place harassment and sexual abuse.

An important indicator used for monitoring progress toward gender equality and the empowerment of women in the Millennium Development Goal framework is the proportion of women employed in paid, non-agricultural work. Available 
evidence indicates gradual increases in women's participation in paid employment outside agriculture in most countries of Asia, though the situation varies considerably across countries. A recent review has indicated that women constitute less than half of the paid workers in the non-agricultural sector in all the Asian countries and their share is very low in a number of countries (Osteria, 2009). In the Pacific, the female proportion of the paid labour force outside the agricultural sector ranges from only 5 per cent in Papua New Guinea to a maximum of 45 per cent in the Cook Islands. Access to paid employment is therefore far from balanced by gender in Asia and the Pacific.

\section{Political participation}

The Key Actions adopted at ICPD +5 reaffirmed the call made at ICPD to “establish mechanism to accelerate women's participation and equitable representation at all levels of the political process and public life in each community and society... and ensure the full and equal participation of women in decision-making processes in all spheres of life" (paragraph 43).

The 10-year review noted that countries have taken a number of measures, including affirmative action and constitutional provisions, to promote the participation of women in political and decision-making positions at all levels. As a result, and with improved education, women's role in political processes and decision-making is gradually improving in a number of countries in Asia. However, a recent regional review has noted that the percentage of women in ministerial level positions and in the national parliaments is lower than 20 per cent in most Asian countries (Osteria, 2009; tables 2a and 2b).

Political participation in the Pacific has shown little improvement over the past decade and the proportion of seats in parliament presently held by women remains below 10 per cent in most Pacific Island countries (table 2c). Papua New Guinea, with 109 seats in parliament has only one woman member, and this has been the case for the last two parliaments. In spite of efforts to appoint women directly to parliament, an option provided for in the Constitution, no such appointments have been made to date.

\section{Gender-based violence}

The ICPD Programme of Action urged countries to "eliminate violence against women" (paragraph 4.4e) and to "...take full measures to eliminate all forms of exploitation, abuse, harassment and violence against women, adolescents 
and children" (paragraph 4.2) and to foster "zero tolerance" towards violence against girls and women.

Gender-based violence (GBV) is recognized as a major human rights issue in many international development agendas, including the ICPD Programme of Action and the Beijing Platform for Action. It includes a wide range of violations of human rights, including trafficking in women and girls, rape, spousal abuse, sexual abuse of children, and harmful practices that irreparably damage the reproductive and sexual health of girls and women (UNFPA, 2004).

Gender-based violence, in various forms and severity, is prevalent and pervasive in all countries; women, throughout their life cycle are exposed to and suffer from its consequences. The 10-year review of ICPD implementation has indicated that there is a growing awareness of the problem among senior policymakers in many Asian countries and that a number of countries have taken measures to minimize its occurrence and to protect those affected. These include enactment of legislation, instilling respectful attitudes towards girls and women among boys through education, and enabling men to support women's rights and their empowerment. The review has also highlighted a number of religious, cultural and social factors that constrain efforts to reduce the incidence of GBV.

Good quality data on various forms of gender-based violence are scarce in Asia and those available from records of reported cases often underestimate its prevalence. Recent surveys, such as demographic and health surveys (DHSs) have begun to collect information which possibly will yield more accurate information in the future. The WHO Multi-country Study on Women's Health and Domestic Violence against Women (WHO, 2005) included one rural and one urban site in Bangladesh and Thailand and one urban site in Japan. In the urban sites, the proportion of women who had ever experienced physical or sexual violence (or both) was 53 per cent in Bangladesh, 41 per cent in Thailand and 15 per cent in Japan. In the rural locations, the rates were 62 per cent in Bangladesh and 47 per cent in Thailand. These rates are among the highest of all the countries surveyed by WHO.

Domestic violence is a common phenomenon in most countries and is often considered as "normal". Most women who are victims of domestic violence do not report such abuse for fear of persecution from the family and the community and further abuse from authorities - even those who are expected and obliged to provide protection. There are also reported cases of sexual harassment and gender-based violence in the work place in many countries. As discussed in the 
preceding sections, gender-based violence is detrimental to women's reproductive health and is a factor in maternal death and the transmission of HIV.

Indirect as well as direct evidence indicate that in some Asian countries and communities there are many instances of extreme forms of violence against women. These include dowry and honour killings and acid throwing, to mention a few. Educational campaigns have been launched and laws have been enacted to prevent these heinous practices, but they continue.

There is also clear evidence of trafficking of girls and women from and to a number of countries in Asia and the number is increasing. As noted in an earlier section, agreements have been reached between some countries of the region to deal with this issue and to provide help for the victims when they are found.

The number of people displaced by natural disasters and civil and military conflicts has increased the number of internally displaced persons and refugees in many Asian countries. Women and girls who live in conflict areas and in camps are not only exposed to severe health risks owing to lack of access to services, including reproductive health and family planning services, but often are also victims of violence, sexual harassment and abuse.

In the Pacific, the ICPD +10 review showed that most Pacific island countries have taken some steps to address gender-based violence; yet recent research suggests that those steps have been insufficient. There has also been some regression as one Government in the Pacific has recently refused to ratify CEDAW on the grounds that it is against its "culture".

Representative studies of GBV have now been conducted in each of the three Pacific subregions using standardized methodology developed by WHO. In the countries studied, the incidence of "physical partner violence" among ever-partnered women aged 15-49 years ranged from 41 per cent in Samoa to 46 per cent in the Solomon Islands and 60 per cent in Kiribati. In the Solomon Islands and Kiribati, 64 and 68 per cent of women, respectively, had experienced physical and/or sexual partner violence. Those rates are among the highest reported in the world by WHO (WHO, 2005). Somewhat lower, but still high rates of violence against women were found in the recent Marshall Islands DHS: 28 per cent of women aged 15 or over reported having experienced violence and 72 per cent of them indicated that their husband or partner was the perpetrator (Marshall Islands, 2009). Although most men and many women believe that physical violence on women by men is approved or permitted by "culture", the 
incidence of violence is higher in urban areas than in the more "traditional" rural villages. Factors conducive to violence include unemployment and access to alcohol. Some evidence suggests that more educated women are less likely to experience sexual violence than those less educated. Nevertheless, there is little doubt that violence against women remains a serious social issue in the Pacific across all social groups.

\section{Progress, challenges and priority strategies}

\section{Progress}

Periodic reviews undertaken in Asia and the Pacific, results of which are summarized in the above sections, have shown that progress is being made in advancing the Cairo Agenda in nearly all the countries of the region. Important gains are the following:

1. Reorientation of population programmes, particularly family planning programmes, away from a "target driven" approach to "a rights-based, need-based approach", including in countries which had previously resorted to methods that were coercive or had used various forms of incentives and disincentives to clients and service providers to meet specified targets. The practice of target driven and coercive approach, it can be said, is a thing of the past and there will be no return to "pre-Cairo" ways of meeting population and fertility goals.

2. Progress towards achieving universal primary education in nearly all countries of Asia and the Pacific and in reducing the gender gap at primary level of schooling. Most countries have achieved universal primary education for both boys and girls and others are well on their way to achieving it.

3. Reduction of infant and child mortality in most countries, though it remains high in some countries and among the poorer segments of the population.

4. Slower pace of the spread of HIV and AIDS in countries with high prevalence, although it continues to constitute a significant threat to women's and men's health in a number of countries. The HIV epidemic continues to spread in some subnational areas and countries.

5. Reproductive and sexual health needs of adolescents and young people firmly placed on the national agenda of most countries of the region. 
6. Recognition that gender-based violence and its impact on women's health and welfare are important issues to be addressed in national agendas.

7. Reduction in poverty, as measured by the proportion of people living below $\$ 1.25$ a day, in most countries and for the region as whole.

\section{Challenges}

While the above are notable achievements, there are major challenges that need to be addressed to achieve the ICPD goals and the Millennium Development Goals by 2015. For example:

1. Inequities in access to health and other basic services remain high and are possibly increasing in many countries, in spite of rapid rates of economic growth and reductions in poverty in most Asian countries.

2. Universal access to reproductive health, as called for in the ICPD Programme of Action, is far from being achieved in the Asian and Pacific region. Achieving this goal will remain elusive until the inequities in access to basic services, including health services, are significantly reduced.

3. The unmet need for family planning remains high and funding for family planning programmes has declined even as demand for such services has increased owing to an increase in the number of people entering the reproductive ages and increasing demand for contraceptive choice. Reproductive health commodity security, including for family planning commodities, is yet to be realized in many countries.

4. Access to services for making pregnancy, delivery and the post-partum period safe is limited for women in poor households and hard-to-reach locations. In particular, access to emergency obstetric care is severely restricted for many women owing to reasons of cost, distance and delay in providing appropriate care.

5. Asian and Pacific women, who have "low-risk" of contracting HIV, are at "high-risk" owing to the sexual behaviour of their husbands, and most of them do not have access to information and counselling to protect themselves. HIV continues to spread rapidly in some areas and STI prevalence is high in some countries.

6. Adolescents and young people constitute the largest ever cohort in many Asian countries. Yet, most of them have limited or no access to secondary 
and/or vocational education, decent employment, and are denied access to information, counselling and services on reproductive and sexual health.

7. Rates of gender-based violence are unacceptably high in many countries of the Asian and Pacific region. Women also face discrimination, and are often denied access to services.

8. Ageing and international migration are emerging as priority issues in many countries of the region. Yet, there is only limited information and knowledge about these emerging trends and the impact they might have on development.

9. National capacity to address the many challenges identified above, though not addressed in detail in this paper, remains limited in a number of countries.

10. Resources for family planning are declining even as the requirements are increasing, and public expenditure for health as a percentage of GDP in most Asian countries is very low.

\section{Priority strategies}

The following are a set of priority strategies to address the above challenges:

1. Restore family planning as a major component in national development agendas such as national development plans and poverty reduction strategies, and allocate adequate resources. This is important to enable women to exercise their reproductive rights, and to help them protect themselves from unwanted/unplanned pregnancies and contracting HIV, and in order to minimize the risk of ill health and/or death due to pregnancy and delivery. Stronger family planning programmes will also contribute to the goal of reducing child mortality.

2. Improve access to prenatal, safe delivery and post-natal care for pregnant women especially from poorer households and marginalized segments of the population.

3. Promote and facilitate the integration of safe-motherhood, family planning and HIV prevention services.

4. Strengthen quality of care of reproductive health services, including family planning and take steps to monitor progress.

5. Expand access to reproductive health information and services, including counselling, for adolescents and young people, particularly girls, and 
advocate for improved access to secondary education and gainful employment.

6. Address gender-based violence by advocating for changes to national laws, policies and practices and by empowering women to realize their full potential through expanded access to education and employment. Address the special needs of women in vulnerable situations, such as natural disasters and civil and armed conflicts.

7. Promote the involvement of men and boys in enhancing reproductive rights and the reproductive health of women.

8. Plan for the ageing society of the future as there is no "luxury of time" and "no luxury of resources". This will include, among others, investing in youth, to benefit from the demographic dividend, promoting healthy ageing, reorienting health systems and services to meet the health needs of older persons, establishing and expanding old-age social security, and supporting the participation of older persons to remain active.

9. Optimize the benefits afforded by international migration through policies that are supportive of migrants and the promotion of the rights of migrants and their families.

10. Adopt a pro-poor approach to planning and programming for the delivery of services, including safe-motherhood and family planning, to reduce the inequities in access.

11. Advocate actively for increases in the allocation for health, including for family planning, in the national budgets, and with the international community to meet their commitments.

12. Build the population and development knowledge base and its utilization through improved data collection, analysis, research and capacity development.

13. Strengthen cooperation among countries, and with NGOs, civil society organizations, the private sector, members of parliament, and other development partners for advocacy, building knowledge base and, as appropriate, for the delivery of services.

Finally, it should be highlighted that capacity development efforts, particularly in the above mentioned areas, should receive high priority. In a number of Asian and Pacific countries, national capacity to implement the ICPD Programme of Action remains limited, even 15 years into the 20 -year blueprint. 


\section{Endnote}

1. The paper is based on a larger report on the 15-year review of the implementation of the ICPD Programme of Action prepared for ICOMP with funding from UNFPA. The views expressed in this report are, however, those of the authors and do not imply the expression of any opinion on the part of ICOMP or UNFPA. The authors wish to acknowledge the guidance provided by Mr. Wasim Zaman, Executive Director of ICOMP, and the valuable suggestions and comments provided by the Asia-Pacific Regional Office of UNFPA. 


\section{References}

Abbott, David (2006). Analysis of the 2002/03 Household Income and Expendure Survey: Estimation of Basic Needs Poverty Lines and Incidence of Poverty in Fiji (Suva, UNDP Pacific Sub-Regional Centre).

Asian Development Bank (ADB) (2009). Investing in Materna, Newborn and Child Health; Case for Asia and the Pacific (Manila, ADB).

Australian Agency for International Development (AusAID) (2009). Tracking Development and Governance in the Pacific (Canberra, AusAID).

Commission on AIDS in Asia (2008). Redefining AIDS in Asia: Crafting and Effective Response (New Delhi, Oxford University Press).

Economic and Social Commission for Asia and the Pacific (ESCAP) (1998). "Asia-Pacific Population Polices and Programmes: Future Directions", Asian Population Studies Series, No. 153 (United Nations publication, ST/ESCAP/1923).

(2003). "Fifth Asian and Pacific Population Conference: Report and Plan of Action on Population and Poverty", Asian-Pacific Population and Social Studies Series, No. 159.

(2007). "The Macao Outcome Document", High-level Meeting on the Regional Review of the Madrid International Plan of Action on Ageing (MIPAA), Macao, China, 9-11 October.

(2009a). ESCAP Population Data Sheet (Bangkok).

(2009b). Asia-Pacific Population Journal, Vol. 24, No. 1, April.

(2009c). "Draft Report of the Asia-Pacific High-Level Forum on ICPD at 15: Accelerating Progress towards the ICPD and Millennium Development Goals", Bangkok, 16 and 17

September, accessed online on 18 November 2009 from www.unescap.org/esid/psis/ meetings/pop_forum_2009/index.asp

Economic and Social Commission for Asia and the Pacific (ESCAP) and United Nations Population Fund (UNFPA) (2004). "Implementing the ICPD Agenda: 10 Years into the Asia-Pacific Experience, A Status Report”, Asian-Pacific Population and Social Studies Series, No. 162 (United Nations publication, Sales No. E.04.II.F.46).

European Union and UNFPA (2007). RHIYA: Comparative Report (New York, UNFPA).

Government of Papua New Guinea (2009). National HIV Prevention Strategy 2010-2015 (Port Moresby, Government of Papua New Guinea).

Guest, Philip (2003). "Reproductive Health including Family Planning", Asia-Pacific Population Journal, Vol. 18, No. 2, pp. 55-79.

Hayes, G. (2005). "The 2010 Census Round in the Pacific Islands", in Advocacy and Resource Mobilization for the 2010 Round of Censuses, Advocacy and Resource Mobilization International Meeting toward the Successful Implementation of the 2010 Round of Population and Housing Censuses in Developing Countries, UNFPA/UNSD, New York, 24-25 February, pp. 194-197. 
Heyzer, Noeleen Ms. (2009). "Welcome Remarks", Asia-Pacific High-level Forum on ICPD at 15, Bangkok, 16 September.

Huguet, Jerrold W. (2003). "International Migration and Development: Opportunities and Challenges for Poverty Reduction", in Fifth Asian and Pacific Population Conference: Selected Papers, Asian-Pacific Population and Social Studies Series, No. 158, pp. 117-136.

Huguet, Jerrold W. (2009). "Progress Towards Achieving the Fifth APPC Plan of Action Goals on International Migration”, Asia-Pacific Population Journal, Vol. 24, No. 1, pp. 197-220.

Jejeebhoy, Shireen J. and Sarah Bott (2002). "Sexual and Reproductive Health of Young People in the Asia Pacific Region", in Fifth Asian and Pacific Population Conference: Selected Papers, Asian-Pacific Population and Social Studies Series, No. 158, pp. 275-308.

Jones, Gavin W. (2009). "Population and Poverty: the Situation in Asia and the Pacific", Asia-Pacific Population Journal, Vol. 24, No. 1, pp. 65-86.

Karim, Raj Abdul (2009). "Reproductive Health, Including Adolescent Reproductive Health: Progress and Challenges in Asia and the Pacific", Asia-Pacific Population Journal, Vol. 24, No. 1, pp. 153-196.

Lucas, David and Helen Ware (1981). "Fertility and Family Planning in the Pacific", Studies in Family Planning, Vol. 12, No. 8/9, pp. 303-315.

Mane, Purnima (2009). “Opening Statement”, Asia-Pacific High-level Forum on ICPD at 15, Bangkok, Thailand, 16 September.

Mujahid, Ghazi (2006). "Population ageing in East and South-East Asia: Current Situation and Emerging Challenges", Papers in Population Ageing, No. 1 (Bangkok, UNFPA CST).

Mujahid Ghazi and K.A.P. Siddhisena (2009). "Demographic Prognosis for South Asia: A Future of Rapid Ageing”, Papers in Population Ageing, No. 6 (Bangkok, UNFPA APRO).

National Aids Council Secretariat (2007). The 2007 Consensus Report on the HIV Epidemic in the Papua New Guinea. (Port Moresby, NACS).

New South Wales Population Health Division (2009). "The Health of the People of New South Wales - Report of the Chief Health Officer" (Sydney: NSW Department of Health).

Osteria, Trinidad (2009). "Towards Gender Equality in Asia and the Pacific: Response, Progress and Challenges", Asia-Pacific Population Journal, Vol. 24, No. 1, pp. 117-152.

Pacific Health Ministers (2008). "The Pacific Policy Framework for Achieving Universal Access to Reproductive Health Services and Commodities 2008-2015" (Nadi, Fiji). Papua New Guinea (2007). The 2007 Consensus Report on the HIV Epidemic in Papua New Guinea (Port Moresby, National Aids Council Secretariat).

Partners in Population and Development (PPD) (2008) ICPD@15: Progress and Prospects (Dhaka, PPD).

Republic of Indonesia (2006). "Risk Behaviour and HIV Prevalence in Tanah Papua 2006" (Jakarta, Ministry of Health). 
Republic of Marshall Islands (2008). "Key RMI DHS Indicators", in Marshall Islands Demographic And Health Survey 2007 (Majuro, Economic Policy, Planning and Statistics Office) accessed from www.spc.int/prism/country/mh/stats/ on 29 August 2009.

Republic of Marshall Islands (2009). "Key RMI DHS Indicators”, “Key RMI DHS Indicators. Accessed at: www.spc.int/prism/country/mh/stats/ on 12 December 2009.

Robertson, A.S. (2007). "Current Status of Sexual and Reproductive Health: Prospects for Achieving the Programme of Action on the ICPD and the Millennium Development Goals in the Pacific", Asia-Pacific Population Journal, Vol. 22, No. 3, pp. 31-44.

Secretariat of the Pacific Coomunity (2008). "HIV Epidemiological Update for Pacific Island Countries and Territories" (Noumea, SPC).

Sladden, Tim (2005). "Twenty years of HIV surveillance in the Pacific - what do the data tell us and what do we still need to know?", Pacific Health Surveillance and Response, Vol. 12, No. 2, pp. 23-37.

Solomon Islands Ministry of Health (2008). "Second Generation Surveillance of Ante Natal Women and Youth", Honiara, Ministry of Health.

UNICEF (2009). The State of the World's Children, 2009: Maternal and Newborn Health (New York, UNICEF).

United Nations (1995). Report of the International Conference on Population and Development, Cairo, 5-13 September 1994 (United Nations publication, Sales No. 95.XIII.18).

United Nations (1999). Key Actions for the Further Implementation of the Programme of Action of the International Conference on Population and Development (A/S-21/5/Add.1).

United Nations (2009). The Millennium Development Goals Report 2009 (United Nations publication, Sales No. E.09.I.12).

UNFPA (2004). Investing in People: National Progress in Implementing the ICPD Programme of Action 1994-2004 (New York, UNFPA).

(2004). ICPD+10: Progress in the Pacific (Suva, Office for the Pacific).

(2008a). "Repositioning Family Planning in the Pacific", UNFPA Technical Series Paper No. 003/2008. (Suva, Office for the Pacific ).

(2008b). "Achieving the Millennium Goals in the Pacific Islands: Policies and Strategies in Reproductive Health" (Suva, Office for the Pacific ).

(2009). "Selected Population and Reproductive Health indicators for Asia and the Pacific 2008 (Bangkok, Asia and the Pacific Regional Office).

(2009). "Population Ageing in the Pacific Islands: A Situational Analysis", (Suva. Office for the Pacific)

World Bank (2006). "Expanding Job Opportunities for Pacific Islanders through Labour Mobility at Home and Away", Sydney: The World Bank. 
World Health Organization (2005). WHO Multi-country Study on Women's Health and Domestic Violence against Women: Summary Report (Geneva, WHO).

(2006). Second Generation Surveillance Surveys of HIV, Other STIs and Risk Behaviours in Six Pacific Island Countries 2004-2005 (Manila, WHO Western Pacific Regional Office). 


\section{Linked Response to Reproductive Health and HIV/AIDS: Capacity- Building in Sub-Saharan Africa and Lessons Learned for Asia and the Pacific ${ }^{1}$}

Linking gender, reproductive health and HIV/AIDS programmes and services and making it friendly to young people can address missed opportunities in HIV prevention and care as well as improve the reproductive health status of people.

By Wasim Zaman and Hairudin Masnin*

The Programme of Action of the International Conference on Population and Development (ICPD) held in Cairo in 1994 called for the establishment of strong linkages between sexual and reproductive health $(\mathrm{SRH})$ and HIV/AIDS by

\footnotetext{
* Wasim Zaman, Executive Director, International Council on Management of Population Programmes (ICOMP), Kuala Lumpur, Malaysia, e-mail: zaman@icomp.org.my and Hairudin Masnin, Programme Officer, ICOMP, e-mail: hairudin@icomp.org.my.
} 
enhancing the capacity of health-care providers, including all family planning providers, in the prevention and detection of, and counseling on, sexually transmitted diseases, including HIV/AIDS, especially among women and youth.

This call was further echoed in 2004 at the ten-year review of the ICPD through the New York Call to Commitment: Linking HIV/AIDS and Sexual and Reproductive Health and the Glion Call to Action on Family Planning and HIV/ AIDS in Women and Children. The commitment of the international community to further intensify linkages between SRH and HIV/AIDS at the policy and programme levels was also expressed in the policy position paper "Intensifying HIV Prevention: A UNAIDS Policy Position Paper" (UNAIDS, 2005). Those policy statements called upon both the SRH and HIV/AIDS communities to strengthen their programmatic linkages.

Linking SRH and HIV/AIDS has the potential to significantly curtail the spread of the AIDS epidemic as well as to meaningfully contribute to the achievement of internationally agreed development goals and targets, including that of universal access to reproductive health by 2015, as set out in the ICPD Programme of Action. According to the World Health Organization (WHO), HIV testing and counselling are the key entry points for individuals and their families to access HIV/AIDS prevention, treatment and care services, and if universal access to reproductive health is to be achieved, many more people will need to know their HIV status.

In 2005, the World Health Organization (WHO), the United Nations Population Fund (UNFPA), the Joint United Nations Programme on HIV/AIDS (UNAIDS) and the International Planned Parenthood Federation (IPPF) published a framework for priority linkages proposing a set of key policy and programme actions to strengthen the connection between SRH and HIV/AIDS programmes. Those linkages work in both directions, by linking HIV/AIDS with on-going SRH programmes and/or conversely, linking SRH with on-going HIV/AIDS programmes (see figure 1).

The "linked response" would benefit from the synergy between sexual and reproductive health and HIV/AIDS programmes and services to encompass notions of integration, collaboration and coordination, in which both programmes and services are complementing each other to achieve greater results. Neither reproductive health nor HIV and AIDS-related objectives can be achieved through the current separation of HIV/sexually transmitted infections and maternal and child health/family planning-related services. Considering the urgency of tackling 


\section{Figure 1: Framework for priority linkages}

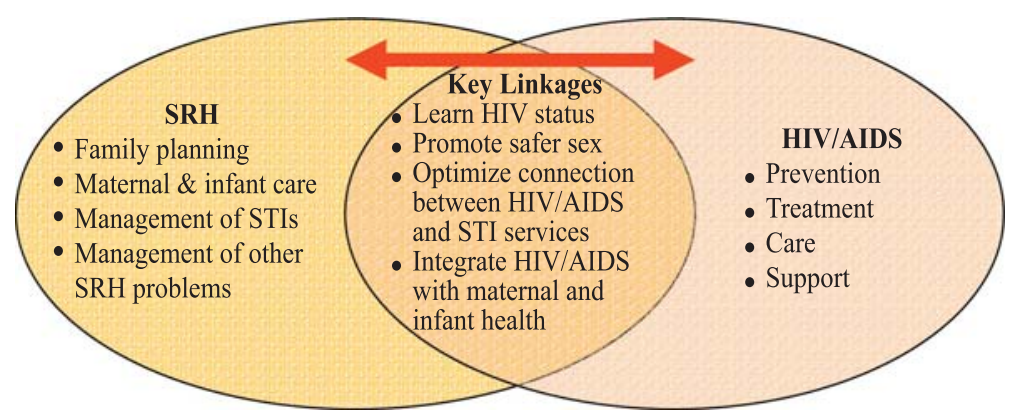

Source: WHO, UNFPA, UNAIDS and IPPF, 2005.

the AIDS epidemic, a consensus needs to emerge around the central question of linked response to reproductive health and HIV/AIDS-related challenges, which needs to be addressed with a great sense of clarity.

Linking HIV/AIDS services to the broad range of sexual and reproductive health services, and vice versa, provides a unique opportunity to promote reproductive health, prevent HIV infection and further promote access to comprehensive reproductive health care to those infected with HIV. For example, reproductive health/family planning/mother and child health programmes can provide referral to voluntary counselling and testing as well as help prevent mother-to-child transmission so that a greater number of clients access HIV/AIDS information and related services. In turn, HIV/AIDS programmes can provide referral to family planning and maternal health services to address unmet reproductive health needs, including sexuality counselling and outreach venues to high-risk groups who do not typically use family planning services yet can be high transmitters such as sex workers and their clients, adolescents, men and HIV-positive women.

A deficiency in implementing linked response to reproductive health and HIV/AIDS services is the failure to acknowledge the need for collaboration between reproductive health/maternal and child health/family planning departments and HIV/AIDS departments (Strachan and others, 2004). In many countries, reproductive health/maternal and child health/family planning and national HIV/AIDS departments operate two distinct/vertical programmes, with often little overlap at the national and local levels. Closer collaboration between the departments is crucial in order to promote effective referral mechanisms. 
Countries often set up family planning/maternal child health and HIV/STI programmes with separate funding, budgets, personnel and administrative structures. Donor orientation and priorities often encourage such vertical structures, discouraging programme managers from considering opportunities to link whenever it makes sense (Lule, 2002). However, some countries have established linkages between vertical programmes through technical committees and other coordination mechanisms.

\section{Adaptation of the framework for priority linkages into local settings}

There is a growing concern about the feminization of the AIDS epidemic as the rates of HIV/AIDS prevalence increase significantly among women, especially in sub-Saharan Africa. In 2007, half of the 30.8 million adults living with HIV/AIDS globally were women (UNAIDS and WHO, 2007). Data show that 76 per cent of all HIV-positive women live in sub-Saharan Africa, where women comprise 59 per cent of adults living with HIV.

It is estimated that 10.3 million people aged 15-24 years are living with HIV/AIDS, and half of all new infections are occurring among young people over 7,000 occur daily. Sub-Saharan Africa is among the hardest hit subregion in the world. It is home to over 70 per cent of all young people living with HIV/AIDS and to approximately 90 per cent of all AIDS orphans (12.1 million children throughout the world). Young people are vulnerable to HIV because of their risky sexual behaviour, substance use and lack of access to HIV-related information and prevention services. Ignorance about the epidemic remains pervasive among this age group, many young persons being unaware of ways to protect themselves from contracting the virus. Marginalized young people (including street children, refugees and migrants) may be at particular risk because of stigma, their exposure to unprotected sex (in exchange for food, protection or money) and the use of illicit drugs.

Promoting gender equality and empowering women as well as involving men and boys are paramount to achieving equitable social, economic and political development, and more critically to improving reproductive health and HIV/AIDS status.

Thus, based on the current trends of feminization of the AIDS epidemic and the rising number of HIV infections among young people in sub-Saharan Africa, the International Council on Management of Population Programmes (ICOMP) 
has initiated a series of projects to enhance the capacity of partner organizations in sub-Saharan Africa to link reproductive health with HIV/AIDS programmes and services. ICOMP has adapted the Framework for Priority Linkages by incorporating gender and youth elements into the Framework (figure 2) to address the feminization of the AIDS epidemic and the rising number of HIV infections occurring among young people.

Figure 2: Youth-friendly engendered linked response framework

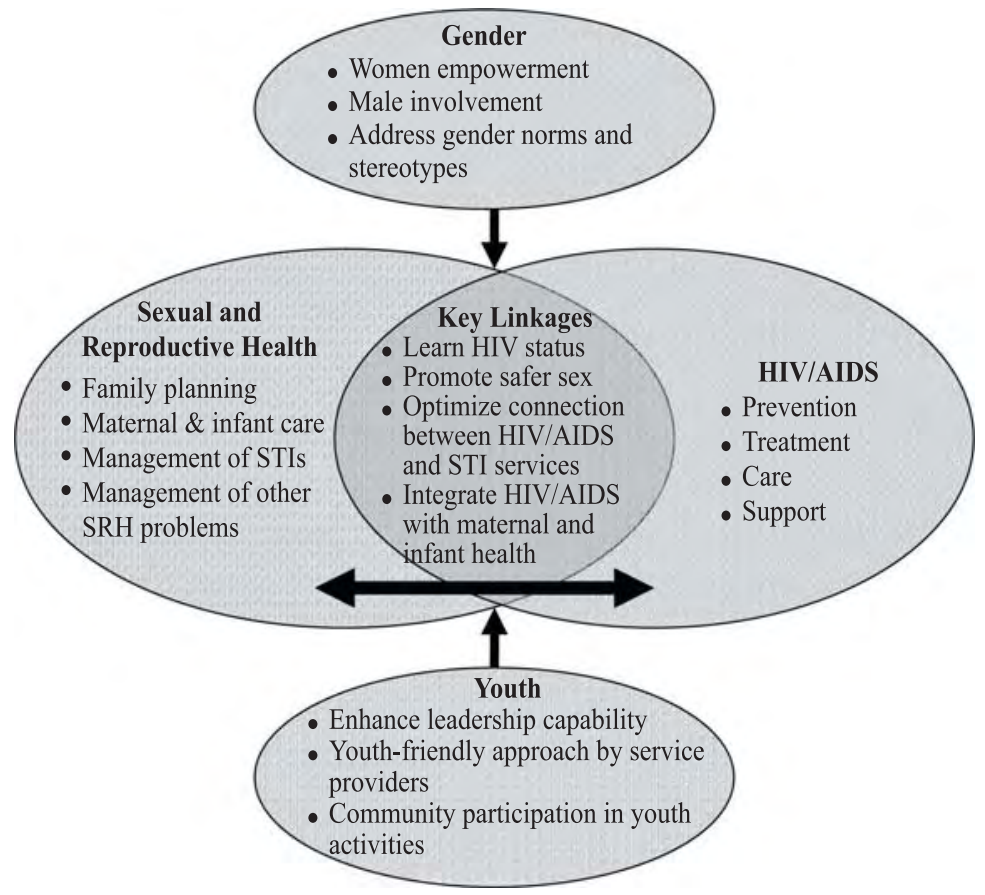




\section{Capacity-building for linked response to reproductive health and HIV/AIDS in sub-Saharan Africa}

Despite some attempts to link family planning with STI and HIV/AIDS services, policies and programmes continue to treat them as unrelated areas of interventions (Strachan and others, 2004). Attention to family planning has been overshadowed as international attention has increasingly been focused on HIV and AIDS, particularly in Africa where the epidemic is most acute.

With funding support from the Population and Reproductive Health Capacity Building Program (PRHCBP) of the World Bank, ICOMP has been implementing five projects to strengthen the capacity of non-governmental organizations (NGOs) for linked response in sub-Saharan Africa from 2005 to 2009. The projects were implemented in collaboration with local NGOs from Ethiopia, Uganda, the United Republic of Tanzania and Zambia. More than 30 NGOs comprising of health-service providers, youth organizations, a network of people living with HIV and faith-based organizations have benefited from the projects.

The first project started in 2005 and aimed to create a sustained impact on SRH and HIV/AIDS by increasing organizational capacity to provide linked responses to reproductive health and HIV/AIDS-related issues. The project was implemented in collaboration with eight NGOs in Ethiopia, Uganda, Tanzania and Zambia.

Building on the success of the above project, in 2006, ICOMP expanded the innovations in linked response to reproductive health and HIV/AIDS through a project which was implemented in collaboration with 15 partner NGOs in Ethiopia, Uganda and Zambia. Following on the assessment of the first and second projects which stressed the critical need for involving men and empowering women to access information on sexual and reproductive health and rights, ICOMP initiated another project that focused on women empowerment and male involvement.

As young people continue to be vulnerable to HIV infection, ICOMP sought funding support from the World Bank to address the SRH needs of young people to improve reproductive health conditions and mitigate new sexually transmitted infections among this age group.

ICOMP uses a three-pronged strategy to build capacity for linked response, as follows: 
- Training of programme managers for implementing integrated linked response interventions such as integrating family planning into voluntary counseling and testing; preventing mother-to-child transmission; promoting condoms and their distribution for dual purpose, and combining SRH and HIV/AIDS messages;

- Sensitization of community members including men, women, boys and girls to linkages between gender, youth, reproductive health and HIV/AIDS-related issues; and

- Enhanced collaboration and networking with stakeholders to build a stronger foundation for linked response.

\section{Training of programme managers}

ICOMP has developed a capacity-building training module to strengthen the management and leadership capacity of programme managers and staff members of partner NGOs to ensure effective and efficient implementation of linked response interventions, on a sustainable basis. A number of training sessions were conducted using a seven-step strategic planning model for linked response (figure 3), delivered over a three-day in-country strategic planning workshop.

Figure 3: Seven-step strategic planning model for linked response

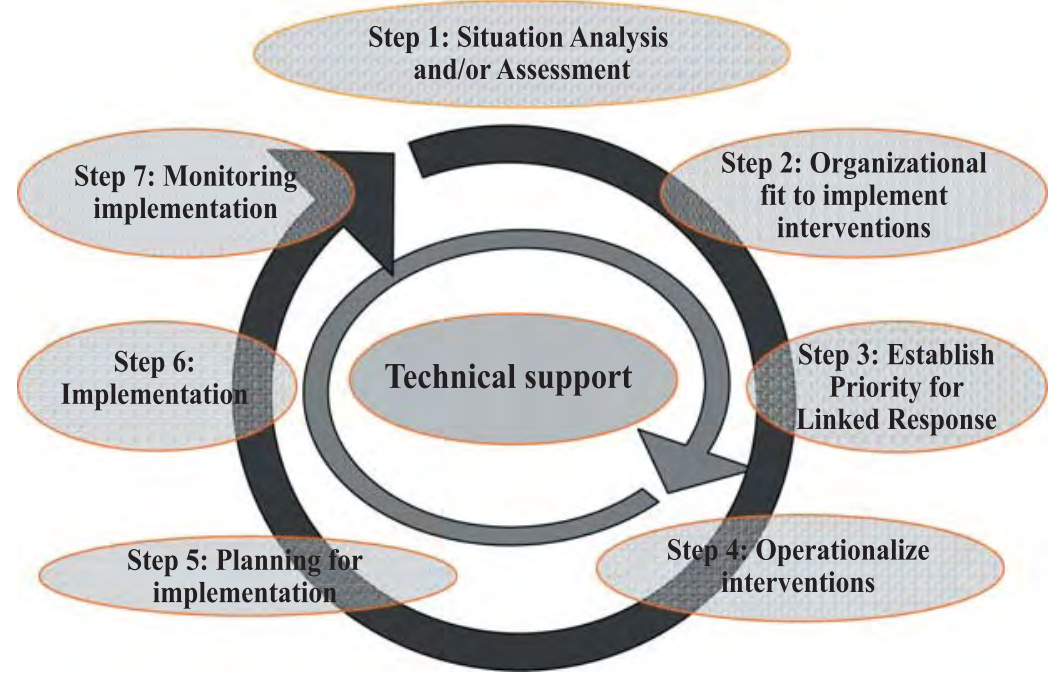


In step 1, participants/partners gather the necessary information on the reproductive health and HIV/AIDS situation so as to inform the decision-making process and avoid repeating past mistakes and minimize risk. In step 2, participants identify potential linked response interventions based on their organizational capacity to implement the various interventions. Under step 3, participants identify priority actions for linked response based on the magnitude of the issue and its urgency, community needs and overall feasibility. Under step 4, participants operationalize interventions by creating demand for linked response by sensitizing the community, organizing its delivery and mobilizing the necessary resources. In step 5, participants develop an action plan for linked response interventions, which they implement under step 6 . In step 7, partners monitor and evaluate the implementation of their activities. Technical support was provided by ICOMP throughout the various steps.

\section{Sensitization of community members}

In order to gain support from community leaders and members for linked response, ICOMP and partner NGOs are using a community-based participatory approach to sensitize community members to sexual and reproductive health and rights issues and their linkages with HIV prevention. ICOMP and partner NGOs organize community sensitization programmes through media such as community dialogue, drama and music, sports tournament and peer education sessions to reach out to a maximum number of men, women, boys and girls living in the community with regard to issues related to gender, young people, reproductive health and HIV prevention. The participation of community leaders and members in those activities is greatly encouraged and actively promoted. For example, in Zambia the partners are working with religious leaders and community members to reduce the stigma associated with condoms, sexually transmitted infections and HIV.

\section{Enhanced collaboration and networking with stakeholders}

ICOMP and partner NGOs continuously advocate building a stronger foundation for linked response to reproductive health and HIV/AIDS among stakeholders, through round tables and one-on-one meetings. Those efforts have helped create a momentum for the implementation of linked response at various levels. Progress in implementation, positive results and experiences gained are systematically shared with other stakeholders at local, district and national levels through round tables and dissemination of documentation. Referral linkages for reproductive health and HIV/AIDS services were established with other local health facilities, including government facilities. The experience of ICOMP has 
highlighted the importance of building and strengthening existing collaboration and networks with other facilities in order to provide services that are not available within the initial setup of partner organizations.

\section{Results}

The capacity-building initiatives discussed earlier have brought about changes at various levels - organizational, service delivery, community and stakeholders.

At the organizational level, it has been observed that partners' understanding of linkages between SRH and HIV/AIDS as well as gender has been improved. Partner organizations appreciate the concept of linked response, which they mainstream in virtually all activities implemented in relation to reproductive health and HIV/AIDS. In addition, resources are now utilized in a more efficient manner, thanks to improved coordination, minimal administrative duplication, sharing of facilities and training of selected staff to perform multiple tasks, etc.

At the service-delivery level, the service mix was improved - reproductive health and HIV/AIDS-related information and services are now offered as a package. Services such as voluntary counselling and testing are linked with family planning, and vice versa, thus enabling clients to access other services offered by health facilities. In addition, quality of care has been improved as service providers are more sensitive to gender issues and are friendlier to young people. Clients' satisfaction has been improved as their different reproductive health and HIV/AIDS needs have been met - clients are also offered a wide range of services. For example, HIV-positive clients coming for antiretroviral treatment were provided with information on SRH and presented with options to receive on-site services or benefit from referral linkages.

At the community and stakeholders level, the initiatives, to some extent, were able to change the perceptions towards issues related to girls' and women's reproductive health, male participation in reproductive health and HIV prevention. Partners have observed an increased number of men and boys utilizing SRH and HIV/AIDS services, as well as being supportive of women exercising their reproductive rights. The initiatives have also contributed to an increased awareness of gender norms and practices and helped reduced the stigma surrounding sexually transmitted infections and HIV/AIDS among community members. 


\section{Lessons learned}

The partner NGOs implemented linked response by mainstreaming gender and linking reproductive health with HIV/AIDS, reviewing their organizational direction, and building skills to deliver linked response to reproductive health and HIV/AIDS programmes and services. Staff members gained increased motivation because their skills and knowledge had improved, and they were able to better serve their clients. Structural changes were also brought about in the organization itself. For example, linkages were formed between different units or departments within the same organization or with other organizations.

The project had challenged partner organizations to broaden the scope of their activities by including new and innovative ways of implementing them. Linked response also triggered other innovative ideas. For example, a youth NGO formed a young boys' model group in which 40 young boys sensitize their peers on girls reproductive health and rights issues and the role of men and boys in HIV/AIDS prevention. This initiative was successfully supported by the international organization Save the Children.

Networking and collaboration with other organizations were also strengthened. Realizing that it was difficult for a single organization to provide comprehensive reproductive health and HIV/AIDS services, partnerships and networks have been developed between different organizations working in the field and government institutions (hospitals, ministries of health, etc.) to generate linked response to HIV/AIDS and reproductive health.

Barriers and resistance to linked response due to a lack of understanding were partially overcome by sharing information and involving key players from the community, Governments and NGOs. Ongoing dialogue and advocacy, a venue or occasion for interaction, dialogue and opinion exchange, such as a dissemination seminar, helped create a common understanding of the issue among various key stakeholders, thus paving the way for closer collaboration.

Small-scale facility-based projects have proven the utility and feasibility of linked response in diverse settings. Such facility-based projects have managed to reach a significant number of community members, thus also increasing the demand for better services, and obviously increasing uptake in service delivery. 


\section{Implications for the Asian and Pacific region}

Based on the experience of ICOMP in Africa, small-scale facility-based interventions can deliver positive outcomes towards meeting the goals and targets of the ICPD and the Millennium Development Goals (MDGs), including universal access to reproductive health. Thus, it appears as an imperative to make the most of existing health-care systems, capitalizing on their strength to promote linked response to reproductive health and HIV/AIDS in Asia and the Pacific.

The region counts a large number of vibrant NGOs working within their communities on health, reproductive health and HIV/AIDS-related issues. The capacity of those NGOs can be built to further accelerate the diffusion of linked response.

With the incidence of HIV across the Asian and Pacific region being largely concentrated among commercial sex workers, injecting drug users and men who have sex with men, integrating SRH and HIV services would ensure that people from overlapping and vulnerable populations do not miss out on essential health services.

\section{The way forward and policy implications}

Linking gender, reproductive health and HIV/AIDS programmes and services, as well as making those friendly to young people can address missed opportunities in HIV prevention and care and improve the reproductive health status of the population. In order to reinforce effective linkages, it is necessary to strengthen the institutional capacity - that is to develop appropriate policies, improve programmes and service delivery as well as strengthen the capacity of reproductive health and HIV/AIDS programme managers. It also implies promoting active participation of community leaders and members in all of the above.

Successful linkages between reproductive health and HIV/AIDS programmes and services can only be achieved through genuine political commitment to actual institutional collaboration rather than through attempts to simply expand and link vertical programmes. Linked response should be institutionalized in all policies related to reproductive health, HIV/AIDS, gender and young people. Such strategies would provide necessary support to make available comprehensive reproductive health and HIV/AIDS services to people, drive better resource allocation and strengthen health delivery systems. 
The management and leadership capacity of such reproductive health and HIV/AIDS programme managers needs to be strengthened to ensure effective and efficient management that precisely promotes those linkages. The broad involvement and participation of community members are also crucial in promoting linkages between reproductive health and HIV/AIDS programmes and services, as is coordinated planning and networking to help institutionalize those linkages.

Successful institutionalization and implementation of the interventions can be achieved through institutional collaboration, bringing together all key stakeholders dealing with issues related to gender, reproductive health, HIV/AIDS and youth. This will also result in cost sharing, capitalizing on existing infrastructures and resources, and reaching out to wider audiences while also being responsive both to clients' needs and to public health.

Efforts should be made to further document and provide evidence of the impact of linked response to reproductive health, towards improving reproductive health status and preventing HIV infections. Investment should also be made to demonstrate other benefits on a wider scale of integrated linked response. Smallscale demonstration at different levels, with solid documentation and analysis, should be undertaken in order to lead to the scaling-up of successful interventions and adaptation in new areas as appropriate, as well as for policy dialogue and advocacy. 


\section{Endnote}

1. The presentation on Linked Response to Reproductive Health and HIV/AIDS Capacity-Building in Sub-Saharan Africa and Lessons Learned for Asia and the Pacific was first made during the $5^{\text {th }}$ Asia-Pacific Conference on Sexual and Reproductive Health and Rights in Beijing, China from 17 to 20 October 2009. The session was organized by the International Council on Management of Population Programmes (ICOMP) with support from the Joint United Nations Programme on HIV/AIDS (UNAIDS) and the World Health Organization (WHO). 


\section{References}

Lule, Elizabeth (2002). "Strengthening Linkages between Reproductive Health and HIV/AIDS." accessed online on 18 November 2009 from http://siteresources.worldbank.org/INTPRH/ Resources/Strengthening_linkages_between_RH_HIV.pdf

Strachan M. and others (2004). "Policy Working Paper Series No. 9: An Analysis of Family Planning Content in HIV/AIDS, VCT, and PMTCT Policies in 16 Countries", accessed online on 18 November 2009 from <http://www.policyproject.com/pubs/workingpapers/wps-09.pdf>.

The Joint United Nations Programme on HIV/AIDS (UNAIDS) (2005). "Intensifying HIV Prevention: A UNAIDS Policy Position Paper", accessed online on 19 December 2009 from <http:// data.unaids.org/publications/irc-pub06/jc1165-intensif_hiv-newstyle_en.pdf $>$.

The Joint United Nations Programme on HIV/AIDS (UNAIDS) and World Health Organization (WHO) (2007) AIDS epidemic update: December 2007.

World Health Organization (WHO) , "The Work of WHO in the Western Pacific Region, 2007-2008", accessed online on 18 November 2009 from <http://www.wpro.who.int/NR/rdonlyres/ 69F4E71F-9705-446B-8578-CD51AC11B71A/0/04dcc.pdf>

World Health Organization (WHO), United Nations Population Fund (UNFPA), the Joint United Nations Programme on HIV/AIDS (UNAIDS) and the International Planned Parenthood Federation (IPPF) (2005). "Sexual and Reproductive Health: A Framework for Priority Linkages". 


\section{A Young Person's Perspective on Population Reproductive Health and the ICPD ${ }^{1}$}

The International Conference on Population and Development (ICPD) has truly been a defining moment for population and development. The challenge, however, is that, since its Programme of Action is comprehensive and addresses a number of important topics, it needs to be unpacked to be understood and owned.

\section{By S. Jacque Koroivulaono*}

My name is Jacque, I come from Fiji and I am 23 years of age. In addition to being a university student I have been a youth advocate/volunteer for several years now in different capacities. I would first like to congratulate all the players driving the ICPD agenda - I can imagine that the process has not been an easy one, trying to translate recommendations into actions and ensuring that those actions have an impact on the ground. Today's review, 15 years after the adoption of the ICPD Programme of Action really displays commitment and perseverance of the people and organizations driving the ICPD agenda. As a peer of mine back home used to say - we need to "walk on, walk strong". Walk on, walk strong.

* Youth Advocate, Pacific, e-mail: jacquekoroi@gmail.com 
At this Forum, I was asked to bring a "young person's perspective" on matters relating to population, reproductive health and ICPD. I don't pretend to represent all young people but have tried my best to take into account their voices through the work I am privileged to carry out. May I say, at this point, that young people make up significant portions of their nations' population, and in some instances half of the population, as in the case of many countries in the Pacific. I realize that there are varying definitions of what constitutes a young person at the national and international levels. In my presentation, however, the young people I am referring to are between 12 and 35 years of age.

My first point relates to the importance of "unpacking a message". ICPD for those who know it - has truly been a defining moment for population and development. It has brought to the forefront reproductive rights, showed the clear connection between population and development and the importance of investing in women, and striving for gender equality. The challenge, however, is that since it is comprehensive and addresses a number of important topics, it needs to be "unpacked" to be understood and owned. It is not unusual to hear my peers say "ICP what?" or "What's the ICPD? Is it some type of contraceptive method?"

Unless ICPD is unpacked for different audiences, including young people and by this I mean that young people are empowered to understand what all the acronyms and substance mean - you will be missing a key group who could be championing this cause. Let me give you three of the many reasons why young people can and should be champions of ICPD:

- We, young people, can be role models for our peers as we share the same interests, space, life questions, opportunities, risks and can relate better to one another;

- We can be like what Nelson Mandela once described - "powerful beyond measure" - not like superman, but energetic, vibrant, creative, resilient, and intelligent with a flavour of naivety... So use us for a worthy cause;

- We will, without a doubt, be leaders of nations, businesses, civil society, families and in your shoes.

Yes, young people can be champions of ICPD.

Let me continue with a second point: young people's participation. A friend of mine from Tuvalu - an island State known for experiencing the effects of climate change - recently said: "Getting young people's voices heard sometimes feels like climbing a tree full of thorns." He is right, we talk about youth inclusion in 
policymaking, but we should not assume that young people always know how to participate.

The United Nations Programme on Youth recently initiated an e-discussion on 11 different topics with young people from different parts of the world. These topics included HIV and AIDS, substance abuse, intergenerational relations, environment, girls and young women, participation in society and decision-making. I was responsible for summarizing the inputs from the Pacific subregion, while I had counterparts doing the same for Asia, Europe, Africa and North America. There were a lot of interesting discussions and much of it was very relevant to our review on the implementation of the ICPD Programme of Action.

What came out from the discussion on participation was that young people need to educate themselves and show an interest - for sure - however, adults too often take it for granted that young people will know how to meaningfully contribute. I am a living example of this: I have always taken a keen interest in girls' and women's empowerment, gender, reproductive health and youth involvement, and have tried to educate myself as much as possible. However, I owe a lot to the many people and institutions that have nurtured my interest and given me confidence not to shy away from contributing.

My peers have repeatedly said that they could only be heard in places where they felt secure and could openly express their views. They often want to be involved in discussions that relate to them. However they need to understand the realities and complexities of national and international development processes to be able to engage effectively and appropriately.

It takes courage for young people to speak up, particularly in cultures where young people are told to keep quiet. But it takes adults to reassure young people that their voices are meaningful, even though they may lack the experience that adults have.

\section{Reproductive health and reproductive rights of young men and women}

The third point that I would like to make is that ICPD has given prominence to adolescent reproductive health, to the issue of teenage pregnancy, to the linkages between HIV and sexual and reproductive health (SRH), to education and gender equality and to the central role of the family. Much progress has been accomplished in those areas. I was eight years old when ICPD took place in Cairo. And like most eight-year old kids, my peers and I were in grade 3, doing maths, English, social science and being quite absorbed in playing hopscotch or 
skipping.... I grew up not knowing much about sexual and reproductive health, except through what I heard in passing now and again. Not much was taught in school or discussed in the home. But I am happy to say that in my early teens I was exposed to trainings, workshops, seminars on sexual and reproductive health organized primarily by non-governmental organizations - could this have been a ripple effect from ICPD? I hope so. Furthermore, numerous workshops/ conferences/seminars on educating young people on their reproductive health and rights, as well as the delivery of youth-friendly services, have increased throughout the region, in particular through the Adolescent Reproductive Health Programme in the Pacific and the Regional Alliance for Youth in Asia. There is also an increase in data made available regarding the SRH status of young people and, most importantly, young people are increasingly being included in the design and implementation of SRH projects, services and discussions.

A number of issues ought to be raised here but I would like to focus on only a few: a major one is the need to bridge the intergenerational gap that still exists. Sexuality education should begin at home, with the school certainly playing a key role. Too often, however, parents do not know how to talk to their children about sexuality issues as they themselves were not taught about sex and often feel uncomfortable talking about it. This is a priority area in my view and I note that ICPD does highlight the role of families, but I would like to encourage more to be done. Can there be a campaign or more efforts devoted to making the "family home" the first point of discussions on sexual and reproductive health? Let us empower parents and guardians - if we have not done so already - to understand the subject matter well and know how to communicate it best to their children. The days of silence around sexuality issues in the household should be over by now.

Yes, parents and young people can also be champions of ICPD.

With regard to sexual and reproductive health, I would also like to encourage the adoption of a different approach to related programmes that would facilitate behavioural change. Behaviour Change Communication (BCC), as I see it, is the practical application in real life of the knowledge acquired; it should not stop at the stage of merely knowing about something. Going to a village and telling sexually active young persons who have already been practicing unprotected sex to use condoms does not change their habits over night. Even if they may know about it, will they have the determination to visit the local health centre to get a condom if they want to have sex? Wow, did I just say the once "taboo" word for me and in a public forum moreover? 
There is also a need to further strengthen the linkages between HIV and sexual and reproductive health. I have mostly found programmes/sessions focusing on one over the other - particularly HIV over SRH. Further linking SRH to international efforts to prevent the spread of HIV would increase young people's access to information and skills regarding their sexual and reproductive health and rights.

Yes, definitely, young people can be champions of ICPD.

\section{Young women's empowerment}

The fourth point I would like to make relates to the empowerment of women, particularly young women.

As I am addressing you today, young women are being educated and empowered with the knowledge of their human rights, taking their offenders to court, undergoing pap smear tests, planning their marriage and how many children they wish to have, being young professionals and saying "no" to forced marriage. But as I stand here before you also, young women in different parts of Asia and the Pacific are subjected to discrimination, early childbearing, prostitution, rape, honour killing, acid throwing, human trafficking, incest, molestation and other sexual violence.

What can I say that you don't already know about the plight of young women in Asia and the Pacific? Over the past couple of weeks, the media in Fiji have reported several cases of young women being raped by their fathers and uncles this greatly frustrated me. I am urging Governments to: (a) pay special and urgent attention to women, including young women and children, and to strive to eliminate the factors that cause their vulnerability; (b) increase allocations in the national budget to raise the economic status of women, including young women; (c) update and enforce laws that protect women/young women and children; (d) take measures to encourage and enable young women to take up positions of leaderships; and (e) promote more programmes on responsible SRH behaviour that involve males.

Allow me to further illustrate some of the above points through the words of a renowned poet from the Pacific, Dr. Konai Helu Thamam from Tonga:
"And can a girl get pregnant
With a kiss
Or lose popularity with the boys
For not wanting to dance
To slow tunes
Or for beating them in class 
Perhaps the problem lies

With parents

Who have different standards

While others have none at all

Their children often fall

For the latest fads

Other adults have no more secrets

Their unconsciousness exposed

To us kids

We can see and read

What's going on inside

Their heads

We're not asking

Too much really

To be happy or have fun

We just want you

To let us matter."

Before I conclude, I would like to highlight another key aspect of ICPD and that is the relation between population and the environment. Population growth, migration, urbanization, the need for more energy, increased consumption patterns and unsustainable development - all those are contributing to environmental degradation and climate change, which have become the focus of decisive high-level discussions in late 2009. I come from a region that is precisely suffering the brunt of climate change - the rise in sea level is already pushing families further inland and in some instances it is forcing them to relocate. Needless to say, adults have the responsibility to leave a healthy planet for future generations.... This is therefore an appeal to continue to analyse and better understand the interlinkages between population and the environment, to strive to address the unmet need for family planning, and to provide an increasing number of migrants with access to sexual and reproductive health services, etc.

In conclusion, I would like to thank once again the advocates of the ICPD Programme of Action over the past few years as their tireless work has certainly helped accelerate the recognition and special needs of young people. It has facilitated the understanding of the sexual and reproductive health and reproductive rights of young men and women, including the delivery of youth-friendly services. In order to make further progress, it is important, as noted above, to continue 
unpacking ICPD, promoting the effective inclusion of young people in policy decisions and programme design, truly empowering young women, setting up systems protecting their rights, and strengthening the linkages between HIV and $\mathrm{SRH}$, as well as between population and the environment.

Nothing for us without us - we are keen just as the late Michael Jackson said to -

"Heal the world,

Make it a better place for you and for me and the entire human race

There are people dying, if we care enough for the living

Make it a better place for you and for me."

We don't just want to be beneficiaries of ICPD but implementers as well, so count us in.

\section{Endnote}

1. This article is based on the keynote address delivered by the author at the Asia-Pacific High-level Forum on ICPD at 15: Accelerating Progress Towards the ICPD and Millennium Development Goals, which was held in Bangkok on 16 and 17 September 2009. 


\section{Progress Accomplished Since the International Conference on Population and Development: A Perspective of Non- governmental Organizations}

The role of NGOs as strategic partners of Governments, international agencies, donor agencies, legislators, the private sector and other civil society groups, has been increasingly recognized and NGOs have had the space to work and significantly contribute towards the pursuit of the ICPD Programme of Action.

\section{By Dr. Raj Abdul Karim*}

Family planning, today encompassed in the context of comprehensive sexual and reproductive health and reproductive rights, has historically always been an area of strength of non-governmental organizations (NGOs), civil society groups

\footnotetext{
* Regional Director, International Planned Parenthood Federation (IPPF) - East and South-East Asian and Oceanian Region, Kuala Lumpur Regional Office, e-mail: RKarim@ippfeseaor.org.
} 
and individuals. From the dawn of the twentieth century, a few "Brave and Angry" women and men activists advocated for women to be able to exercise birth control and the right to voluntary motherhood. They saw the physical, emotional and financial burdens women bore and understood their longing to limit the size of their families and the risks they took to do so. Those women took it upon themselves to share information with other women and distribute "home made" contraceptives even though it put their lives at risk for contravening their government's policies or legislation. Yet they pursued their firm beliefs and their names continue to command respect and provide never-ending motivation and determination to the Margaret Sangers of today.

The family planning movement came to life in Bombay in 1952 with six founding members, namely Senator Shidzue Kato (Japan), Constance Goh Kok Kee (Singapore), Lady Rama Rao (India), Elizabeth M. Jolly (Hong Kong, China), Ilise Ottesen-Jensen (Sweden) and Margaret Sanger (United States of America). Since then, the movement has continued to expand with other like-minded women and groups advocating for women's rights, health, empowerment, equality and for the removal of legislation, policies and sociocultural traditions and practices that affect the right to life and well-being of women, children and families.

Today, organizations working in the area of family planning or reproductive health are providing an array of sexual and reproductive health (SRH) services to women, men and young people in 180 countries around the world. They are advocating for the rights of women to equality and non-discrimination, for non-coercive and voluntary family planning and for Governments to provide family planning and SRH services as an essential service fulfilling a basic human right, as well as for more resources to implement the Programme of Action of the International Conference on Population and Development (ICPD).

NGOs and prominent advocates and activists voicing their concerns during the preparatory meetings for ICPD and at the Conference itself held in 1994 in Cairo have helped attract Government attention to critical issues related to sexual and reproductive health and rights. The role of NGOs as strategic partners of Governments, international agencies, donor agencies, legislators, the private sector and other civil society groups has been increasingly recognized and NGOs have had the space to work and significantly contribute towards the pursuit of the ICPD Programme of Action. Since then, NGOs have moved forward to provide and expand access to SRH, giving priority to groups which remain underserved by the public health systems, including rural and island populations, socially-excluded groups, underprivileged populations living in urban slums and squatter areas, 
migrants and internally displaced persons, and populations living in crisis and post-crisis situations. Their work in complementing that of public health services is today recognized as NGOs continue to further expand their network and outreach programmes to the poor, underprivileged and needy.

In the very personal arena of sexual and reproductive health and reproductive rights, NGOs have also paved the way forward to address more sensitive, controversial and complex issues in spite of many legal, social, cultural and religious ramifications and constraints. This is in line with their objectives of saving the lives of women and newborns, promoting and improving the health of women and of their families, providing women and young people with access to comprehensive and quality SRH services, and protecting and promoting their rights, protecting them also from the dangers and complications of unhealthy and unsafe SRH practices, and providing them with information and education to enable them to make informed decisions.

Since the adoption of the ICPD Programme of Action and despite opposition from the Catholic Church, as well as constraints of the Mexico City Policy, ${ }_{1}^{1}$ NGOs have shown that they can lead the way to prevent tragic and unnecessary deaths arising from complications due to unsafe abortion, to expand access to family planning - especially for women at a higher risk of experiencing complications of pregnancy and childbirth - and to address SRH needs of adolescents and young people. NGOs are working in a variety of fronts in this area - from fighting stigma and discrimination against persons living with HIV and AIDS; preventing sexual violence, coercion and exploitations of girls and women; and involving the most at-risk populations including sex workers, migrants and men having sex with men, in the planning and implementation of programmes aimed at addressing their specific needs. NGOs are also being recognized, not only for their key role in working with and involving young people in adolescent and youth SRH-related programmes, but also for their efforts to empower young people to become leaders, advocates, peer motivators and educators. The International Planned Parenthood Federation (IPPF) for example, has a constitutional standard to ensure 20 per cent youth representation in all governance boards at central, regional and national levels.

The efforts and initiatives at both international and national levels have brought NGOs to the fore to support the review of progress towards the implementation of the ICPD Programme of Action and to identify persisting constraints and barriers, as well as to define strategies for further progress towards achieving universal access to SRH by 2015 . 
Commemorating the tenth anniversary of the adoption of the ICPD Programme of Action, a coalition of international organizations working in the field of SRH, with strong support from the European Commission and other donors, organized a series of activities to review the ICPD Programme of Action, 10 years into its implementation. In particular, Family Care International, IPPF and Population Action International, in close collaboration with individuals representing a broad range of regional and international networks in related fields, were successful in convening the Countdown 2015 Global Roundtable in London in October 2004, which was preceded by six NGO-led regional meetings. A report card assessing countries' performances with regard to ICPD commitments, policy briefs and fact sheets, as well as a communications campaign aimed at refocusing attention on the importance of the ICPD goals, was also part of this initiative.

While this was not a United Nations intergovernmental process, this strategic review by civil society of countries' performances, programmatic success and constraints provided an opportunity to identify future directions, recruit new leadership and welcome new allies. Young people were active players throughout the process.

The Roundtable among other things, sought to have a better understanding of the pivotal linkages between sexual and reproductive health and reproductive rights, as well as other critical development issues, including gender equality and poverty, and to advocate for more resources for related programmes and policies.

The high energy and spiritedness of NGOs was demonstrated again at the Women Deliver Conference held in London in 2007 and convened under the leadership of Family Care International. This NGO-led initiative sought to draw the attention of politicians, Governments, international agencies, civil society communities and individuals to the importance of saving women's and newborns' lives from complications of pregnancy and delivery, as well as to refocus on family planning. The Conference advocated for more resources and a greater commitment to reduce maternal mortality and morbidity in order to accelerate progress towards Millennium Development Goal 5 to improve maternal health. Progress on this particular front is critically lagging in the region. The Conference resulted in a positive commitment specifically by the Department for International Development of the United Kingdom of Great Britain and Northern Ireland to provide additional funds for reproductive health commodities.

In Berlin in September 2009, NGOs once again led the way to commemorate the 15-year anniversary of ICPD with the convening of the Global Partners in 
Action: NGO Forum on Sexual and Reproductive Health and Development, which was co-hosted by the Government of Germany's Federal Ministry for Economic Cooperation and Development (BMZ) and the United Nations Population Fund (UNFPA). The three-day Forum called upon 400 delegates from 131 countries to advocate more strongly for speedy actions and investments to make the Cairo consensus a reality in their community and country, and to end gender-based discrimination. The Forum called for more open discussions regarding sexual behaviour and for the urgent scaling up of successful programmes providing voluntary family planning, comprehensive sex education, and maternal and newborn health care.

"Everywhere injustice is driven by silence", said Dr. Gill Greer, the Chair of the Forum Steering Group and Director-General of IPPF, at the closing of the Forum. Dr. Greer said that NGOs could and should point out, for example, that "unsafe abortion is a major cause of death for girls aged 15 to 19 years in the developing world" and that "meeting the unmet need for family planning could prevent a third of all maternal deaths".

During the final session of the Forum, regional NGO representatives presented the Berlin Call to Action to a group of parliamentarians who promised to relay it to Governments around the world. Dr. Purnima Mane, Deputy Executive Director of UNFPA, recognized the contribution of NGOs and other stakeholders and the need for closer collaboration, as per her final words at the closing session: "We have reignited the spirit of partnership". Mr. Anand Grover, United Nations Special Rapporteur on the Right to Health, called on Governments to guarantee human rights and said that "rights-based approaches to family planning and population needs actually work". Ms. Katie Chan of Youth Coalition, the sponsor of a youth meeting convened prior to the Forum, said that the Forum had energized the young people present to carry ICPD principles forward to the next generation.

The Berlin Forum urged the international community to reinforce its commitment to the vision of the ICPD Programme of Action and in particular, to sexual and reproductive health and reproductive rights. The Forum reiterated that attainment of the ICPD goals was more urgent today than ever before as countries and individuals were searching for effective responses to address financial, political, humanitarian and environmental crises, climate change, insufficient health resources, continuing high maternal mortality and morbidity and the spread of HIV, as well as in ensuring human rights. 
The Berlin Call to Action called on local, national and international decisionmakers to work jointly with NGOs to establish and implement concrete, practical and fully-funded actions for ensuring sexual and reproductive health and rights, and urged them to:

- Guarantee that sexual and reproductive rights, as human rights, are fully recognized and fulfilled;

- Invest in comprehensive sexual and reproductive health information, supplies and services as a priority in health system strengthening;

- Ensure the sexual and reproductive rights of adolescents and young people;

- Create and implement formal mechanisms for meaningful civil society participation in programmes, policy and budget decisions, monitoring and evaluation; and

- Ensure that Governments and donors allocate sufficient resources and budgets so as to meet people's sexual and reproductive health and rights needs.

The Forum also urged donors to meet their commitments to oversee assistance and provide full, predictable and long-term funding. It is also called for prioritization of sexual and reproductive health and reproductive rights as a critical component of economic and social justice, health and development. The participating NGOs committed to work in cooperation with Governments, bilateral and multilateral agencies, and policymakers in order to ensure timely implementation of the Forum's Call to Action and to hold Governments accountable for the full realization of the ICPD Programme of Action. "It is a matter of human rights, democracy and equality for all".

In the Asian and Pacific region, the NGO Forum on ICPD at 15 was convened in Bangkok on 15 September 2009 - one day prior to the Asia-Pacific High-Level Forum on ICPD at 15 organized jointly by ESCAP and UNFPA on 16 and 17 September. The NGO Forum was attended by representatives from 16 countries, NGOs, Governments, donors, United Nations agencies, parliamentarians and civil society organizations and convened by a virtual regional steering committee led by IPPF, East and South-East Asia and Oceania Region. While acknowledging the progress accomplished over the last 15 years, the NGO Forum drew attention to the unfinished agenda of Cairo and identified priority actions to accelerate achievements towards the ICPD and Millennium Development Goals in the Asian and Pacific region. 
The Forum noted that the region was extremely diverse and had unique needs and problems that remained unaddressed. Key issues facing the region include: (a) persistently high levels of maternal mortality in some countries; (b) unmet need for family planning of both married and unmarried women; (c) unsafe abortion; (d) unmet SRH needs of adolescents and young people and of marginalized groups such as refugees, migrants, internally displaced persons and persons with disabilities. The Forum also drew attention to the needs of the least developed countries and landlocked, island and fragile States, as well as countries in crisis situations.

The NGO Forum on ICPD at 15 reaffirmed the importance of a rights-based and gender-sensitive approach in programming and advocacy and of ensuring the participation of beneficiaries in all aspects of programming. Participants at the Forum had the opportunity to voice their concerns and were able to engage in frank discussions with high-level speakers and resource persons from Governments, United Nations agencies, donors and NGOs.

In her keynote address, Dr. Nafis Sadik, Special Adviser to the United Nations Secretary-General and United Nations Special Envoy for HIV and AIDS in Asia, acknowledged that the implementation of the ICPD Programme of Action was unfinished. She reiterated that ICPD had brought forward a paradigm shift where the links between rights, development and sexual and reproductive health were clearly stated but that Governments in Asia-Pacific were not fully implementing the ICPD Programme of Action, although they had endorsed it. Dr. Sadik presented her perspective on the unfinished agenda and called upon the Forum to work on the challenging issues of maternal mortality, gender equality, young people, migration, HIV and AIDS, as well as the emerging issue of population and climate. She also called for more resources as lack of funding for SRH services is currently holding back development in the region.

Mr. Najib Assifi, Deputy Regional Director and Representative to Thailand of UNFPA, Asia and Pacific Regional Office, expressed support for the efforts of NGOs and encouraged initiatives, undertaken in partnership with UNFPA, particularly with regard to issues which are culturally sensitive such as reproductive rights. He cited the example of NGO efforts in Sri Lanka, Maldives and Timor Leste where NGOs helped revitalize inactive Government legislation protecting the rights of women and girls facing violence.

Dr. Jacques Jeugmans, Practice Leader (Health) of the Asian Development Bank presented the Bank's policies and its five core areas of operations, 
underscoring how proposals relating to sexual and reproductive health and rights could be aligned. He suggested targeting multiple partners for resources and stressed the importance of being mindful of accountability and results. Salli Davidson, Health Advisor of New Zealand's International Aid and Development Agency, reminded the Forum about the special needs of the Pacific, the importance of family planning as a cost-effective intervention and the need for the voices of NGOs to be unified with regard to sexual and reproductive health and related messages.

The Forum adopted the Unfinished Agenda of Cairo at ICPD+15: Asia-Pacific NGO Call to Action, which was submitted to the Asia-Pacific High-level Forum on ICPD at 15. In supporting the above-cited Berlin Call to Action, the Asia-Pacific NGO Call to Action identified the following priority areas for action:

- Establish a forum for NGOs as a mechanism for ongoing dialogues for effective collaboration, sharing of experiences, and creating a unified voice for sexual and reproductive health and rights advocacy and resource mobilization;

- Pursue urgently targeted, determined and appropriate media campaigns and advocacy; and engage parliamentarians at the highest level to secure adequate funding and to lobby for favourable laws and policies to meet the ICPD and Millennium Development Goal-related targets - particularly those under Goal 5 to improve maternal health;

- Identify and strategically target alternative sources of funding from corporations and philanthropists, and create income-generating activities to strengthen and sustain NGO programmes;

- Convince donors to fund civil society initiatives on sensitive and contentious issues of sexual and reproductive health and rights and proactive strategies to anticipate emerging needs of populations affected by environment and climate change;

- Urge Governments to recognize NGOs as equal partners and create inclusive mechanisms for meaningful NGO and civil society participation; and

- Strengthen advocacy to ensure that sexual and reproductive health and reproductive rights and gender equality are included in the agenda of global and regional summits to prioritize and secure funding. 
In addition, the NGO Forum on ICPD at 15 also endorsed a broader set of urgent actions aimed at accelerating achievement of the ICPD and Millennium Development Goals, as stated in the Asia-Pacific NGO Call to Action:

- Urge Governments to invest in primary health-care and health systems strengthening to enable the provision of integrated, comprehensive and quality services towards the achievement of universal access to sexual and reproductive health and rights;

- Reposition and revitalize family planning as the most cost-effective intervention to reduce maternal mortality, prevent unsafe abortions and unintended pregnancies with focus on the most vulnerable populations such as unmarried and married young girls and women;

- Urge Governments to remove all remaining discriminatory barriers that prevent girls from attending school and ensure their access to health care, nutrition and education;

- Meet the sexual and reproductive health needs and rights of young people through increased investments in youth participation, capacity-building, youth-friendly services, comprehensive sexuality education, and intensify efforts to reach the most vulnerable and marginalized groups;

- Prevent unsafe abortions through ensuring access to family planning, comprehensive abortion services, advocating for removal of legal restrictions and barriers, and application of new technology;

- Protect young girls and women, particularly those in difficult circumstances, and in crisis and conflict situations, from all forms of exploitation and violence, ensuring access to sexual and reproductive health, psychosocial and legal services for survivors, also ensuring that perpetrators are held accountable;

- Promote, protect and fulfill the rights of all people to have safe and satisfying sexual relations, practice healthy sexual behaviour and prevent the transmission of sexually transmitted infections and HIV; and

- Urge Governments to ensure that safeguards are in place to protect the gains of ICPD even as the region faces economic challenges.

The NGO Forum on ICPD at 15 called on Governments, NGOs and other stakeholders in the Asian and Pacific region to strengthen collaborative relationships in order to more effectively address the complex and inter-connected issues of health and development, taking into account the principles of 
accountability and transparency. The Forum urged all stakeholders to set forth an inclusive agenda for development founded on a rights-based and equity framework. It reiterated the call for the advancement of gender equality and equitable access to services wherein girls and women of all socio-economic and personal circumstances are able to make informed decisions and care for their own health as well as achieve their personal aspirations. The Forum concluded that the time had come for all stakeholders in the region to accelerate the implementation of the ICPD Programme of Action to achieve equality, equity and human rights for all.

As NGOs continue to advocate and provide SRH services especially to poor and marginalized populations, it is clear that they remain determined to get their voices heard by key stakeholders and to be given a place as equal dialogue partners with Governments and donors. NGOs representing communities and families are the voices of the people.

\section{Acknowledgement}

The author would like to acknowledge the contribution of Dr. Gill Greer who kindly provided information on the Global NGO Forum held in Berlin and the Berlin Call to Action.

\section{Endnote}

1. The Mexico City Policy, also known as the Global Gag Rule, was an intermittent policy of the Government of the United States of America that barred federal money from going to international family planning groups that counsel women on abortion or perform the procedure. It was overturned by President Barack Obama in January 2009. 


\section{References}

ESCAP (2009). "Report of the Asia-Pacific High-Level Forum on ICPD at 15: accelerating progress towards the ICPD and Millennium Development Goals", Bangkok, 16 and 17 September 2009, ST/ESCAP/ICPD/2009/1, accessed online on 18 November 2009 from www.unescap.org/esid/psis/meetings/pop_forum_2009/index.asp

International Planned Parenthood Federation (IPPF) and others (2009). "The unfinished agenda of Cairo at ICPD+15: Asia Pacific NGO Call to Action" accessed on 17 December from www.ippfeseaor.org/NR/rdonlyres/3DBDE266-6BC9-44FA-9134126D2FBBEF9E/0/ NGOCalltoActionFinalDocument.pdf.

Wadia, Avabai (2001). “The Light Is Ours: Memoirs and Movements”, London, International Planned Parenthood Federation. 


\section{Asia-Pacific High-Level Forum Declaration on Population and Development: Fifteen Years After Cairo*}

Fifteen years ago, the world came together at the International Conference on Population and Development (ICPD) in Cairo and agreed by consensus on a 20 -year Programme of Action ${ }^{1}$ that integrated a comprehensive range of population, development and human rights issues, necessary for ensuring that each person lives a healthy and dignified life.

Since then, the Asian and Pacific region has seen increased access to sexual and reproductive health and reduced gender gaps in education. This has led to improved living standards, increased opportunities and choices for both women and men, and improved health and well-being for millions of people. It also had a positive impact on poverty reduction and economic development. However, there

\footnotetext{
* This Declaration was adopted on 17 September 2009 during the Asia-Pacific High-level Forum on ICPD at 15: Accelerating Progress Towards the ICPD and Millennium Development Goals, which was held in Bangkok on 16 and 17 September 2009. It is contained in the report of the Forum (E/ESCAP/ICPD/2009/1).

${ }^{1}$ Report of the International Conference on Population and Development, Cairo, 5-13 September 1994 (United Nations publication, Sales No. E.95.XIII.18), chap. I, resolution 1, annex.
} 
remain considerable challenges and gaps, including as a result of the economic crisis, that need to be addressed in order to attain internationally agreed development goals, including the Millennium Development Goals.

This is a moment of opportunity. With only five years remaining until the end of the Programme of Action of the International Conference on Population and Development, ${ }^{1}$ and having passed the mid-point for achieving the Millennium Development Goals, it is urgent for countries to identify gaps and challenges, to consolidate lessons learned over the last 15 years, and to reaffirm their commitments, while redoubling efforts, sustaining achievements and increasing resources to accelerate progress towards the fulfilment of the Programme of Action of the International Conference on Population and Development ${ }^{1}$ and the Millennium Development Goals.

We, the delegates of the Asia-Pacific High-level Forum on ICPD at 15,

Recalling the Programme of Action of the International Conference on Population and Development ${ }^{1}$ adopted in Cairo in 1994 and the key actions for the further implementation of the Programme of Action of the International Conference on Population and Development adopted in 1999, ${ }^{2}$

Also recalling the Fourth World Conference on Women held in Beijing in 1995 and the Beijing Declaration and Platform for Action ${ }^{3}$ and their subsequent reviews, ${ }^{4}$

Further recalling the United Nations Millennium Declaration ${ }^{5}$ and its revised Millennium Development Goals monitoring framework, ${ }^{6}$ including the new target under Goal 5 to "achieve, by 2015, universal access to reproductive health",

Recalling the Plan of Action on Population and Poverty adopted by the Fifth Asian and Pacific Population Conference in 2002, ${ }^{8}$

\footnotetext{
${ }^{2}$ Resolution S-21/2, annex.

${ }^{3}$ Report of the Fourth World Conference on Women, Beijing, 4-15 September 1995 (United Nations publication, Sales No. E.96.IV.13), chap. I, resolution 1, annexes I and II.

${ }^{4} \mathrm{~A} / \mathrm{RES} / \mathrm{S}-23 / 2, \mathrm{~A} / \mathrm{RES} / \mathrm{S}-23 / 3$ and $\mathrm{A} / 60 / 371$, annex.

${ }^{5}$ See General Assembly resolution 55/2.

${ }^{6} \mathrm{E} / \mathrm{CN} .3 / 2008 / 29$, annex I.

${ }^{7}$ See http://www.mdgmonitor.org/goal5.cfm.

${ }^{8}$ E/ESCAP/1271, annex I.
} 
Also recalling the outcomes of all the relevant United Nations conferences and summits of the 1990s, including all conventions, treaties and protocols,

Convinced that the promotion of human rights, the empowerment of women and gender equality are key requirements for development,

Acknowledging the links between improved sexual and reproductive health and gender equality and equity, socio-economic development and poverty reduction,

Also acknowledging the complex interrelationships between population, economic growth and sustainable development, as well as population distribution, environmental concerns including climate change, urbanization and migration, ${ }^{9}$

Noting that the region is home to the largest generation of young people ever,

Also noting that many countries in the region are facing rapid population ageing,

Further noting that the region is vulnerable to frequent natural disasters,

Concerned by the uneven progress within the region in implementing the Programme of Action of the International Conference on Population and Development ${ }^{1}$ and achieving the Millennium Development Goals, especially the relatively slow progress made in the region in reducing maternal mortality and ensuring equitable access to reproductive health information and services for all population groups, including the most vulnerable,

Also concerned by the continued high levels of violence against women and girls and the devastating consequences for them, their families, communities and States,

Recognizing that the global economic crisis will have adverse consequences for aid flows and the anticipated high-level increases in investments in infrastructure, particularly for education and health, which are indispensable for the development of quality human resources needed to power the engine of economic growth and prosperity,

\footnotetext{
${ }^{9}$ The delegation of the Russian Federation expressed a general reservation on this paragraph. It considered that the substantive intergovernmental negotiations on the issue of climate change should take place within the process of the United Nations Framework Convention on Climate Change.
} 
Also recognizing that the crisis could jeopardize current progress and future gains in the achievement of development in many developing countries, with damaging fallout for the achievement of the Millennium Development Goals, including gender-sensitive and gender-responsive policies,

Recalling the documented evidence that investments in the social sector, particularly in health and education, enhance the linkage between population dynamics and sustainable development and lead to higher productivity, more savings and more productive investments, resulting in faster economic growth,

Stressing the crucial need for all development policies and support to address the linkage between the development of human capital in developing countries and financing for development in a more systematic and coherent way,

Reaffirm our commitment to fully implement the Programme of Action of the International Conference on Population and Development ${ }^{1}$ by 2014 through concerted actions in the following areas.

\section{A. Maternal health}

Maternal mortality and morbidity constitute the greatest health inequity. They are indicators of economic and social development, social justice and human rights. Poor reproductive health outcomes are rooted in poverty and the subordination of women, as well as inadequate quality information and services for reproductive health. The survival of mothers and maternal health determine the survival and health of their children, particularly during the newborn period. Almost half of the world's maternal deaths occur in Asia and the Pacific. The region also has the lowest rate of deliveries assisted by skilled birth attendants. If current trends persist, it is clear that the region will not achieve Millennium Development Goal 5 on improving maternal health by 2015 .

Key actions:

1. Provide evidence-based advocacy on the critical role of maternal health in achieving the Millennium Development Goals and the need to increase investments in maternal and newborn health.

2. Strengthen mechanisms to reduce financial barriers to enable poor women access to quality maternal health services. 
3. Expedite the achievement of Millennium Development Goal 5 on improving maternal health, thereby realizing the right to maternal health by ensuring universal access to comprehensive reproductive health services, in particular family planning, prenatal care, skilled birth attendance and emergency obstetric care, through enhanced political commitment and adequate allocation of resources.

4. Highlight maternal health in poverty reduction frameworks and population and health policies, allocate adequate financial resources and ensure their effective utilization.

5. Implement effective policies and programmes to address factors such as women's autonomy and empowerment, as well as accessibility to quality health care that will lead to an improvement in reproductive health outcomes. Improved nutrition and education for girls in childhood and adolescence will also contribute to improved maternal health outcomes.

6. Implement and enforce policies and laws on the minimum age of marriage, thereby preventing risks associated with low age at marriage and adolescent pregnancies.

7. Empower the community by enhancing knowledge and encouraging behavioural change to facilitate access to quality information, care and services.

8. Guarantee the availability of minimal physical infrastructure, including necessary and well-maintained obstetric equipment and the widest possible range of the reproductive health commodities needed to provide the full range of emergency obstetric care services, according to internationally agreed standards, with a particular focus on marginalized groups and the poor.

9. Ensure the availability of quality human resources for the provision of maternal health services, including strengthened partnerships between skilled birth attendants and traditional birth attendants based on adequate forecasting of needs, retention plans for skilled health personnel, and the qualitative improvement of the skills needed to provide such services by medical and paramedical staff, the latter in accordance with internationally agreed standards.

10. Ensure that women have access to services for the management of complications arising from abortion, compassionate post-abortion counselling and care, and necessary information so that they can make informed choices. 
11. Work in partnership with civil society to address the socio-economic barriers to access to and the utilization of sexual and reproductive health services.

12. Integrate the target on achieving universal access to reproductive health by 2015 into national development plans, and monitor and report on the implementation of actions to achieve the target as part of national Millennium Development Goal reports.

\section{B. Family planning}

Investments in family planning are economically sound and play an important role in economic development and poverty reduction. However, despite increases in the contraceptive prevalence rate due to the success of family planning programmes, the unmet need in the region remains high, hindering the achievement of related reproductive health goals.

Key actions:

1. Enhance political commitment to reposition and revitalize family planning as a development agenda for achieving reproductive health outcomes as well as broader poverty reduction goals.

2. Ensure adequate financial investments in family planning, including for reproductive health commodity security, in collaboration with partners as part of broader poverty reduction efforts.

3. Fully integrate family planning programmes and programmes on HIV and other sexually transmitted infections and reproductive tract infections into essential reproductive health services.

4. Build the capacity of service providers to deliver client-focused services with a special emphasis on culturally-sensitive delivery methods to address the needs of the most vulnerable sections of the population.

5. Reduce the high proportion of unmet need in family planning and improve access to a wide range of quality contraceptive services and information, education and communications, especially for poor women and marginalized groups. 


\section{Sexual and reproductive health, including for adolescents}

Asia and the Pacific has the largest generation ever of young people between the ages of 10 and 24. This presents a great opportunity for countries to invest in the productive and healthy development of young people. Commitments made to provide age-appropriate, gender-sensitive and youth-friendly information and services have largely remained limited to plans and policies. Where services are available, they have limited coverage in terms of population and geography and are not socially inclusive, often not reaching vulnerable and most at-risk young people.

Key actions:

1. Take urgent measures to strengthen health systems, to mobilize community support and to realign services to be more equitable, culturally sensitive and socially acceptable to ensure universal access to comprehensive, integrated and quality sexual and reproductive health services.

2. Develop strategies to strengthen community support (which includes parents, senior members of the family, faith-based organizations and non-governmental organizations) for youth-friendly adolescent sexual and reproductive health programmes and services, including comprehensive, rights-based, gender-sensitive and participatory sexuality education.

3. Integrate youth issues and policies into national development strategies and policies.

4. Scale up evidence-based programmes, including information and education, which provide a comprehensive approach to young people's sexual and reproductive health, including age-relevant, gender-sensitive and context-specific information, and life-skills education for young people in and out of school, especially in rural areas.

5. Provide youth-friendly sexual and reproductive health information and services which are accessible to young people, both integrated into primary health care and as youth-specific services, where required, with a focus on reaching excluded and marginalized young people, especially young girls.

6. Create space for and empower young people to participate meaningfully in policy and programme formulation at various stages and levels in the context of national development processes. 
7. Encourage leadership at all levels — national, provincial and local—especially in the areas of HIV/AIDS prevention.

8. Ensure universal access to prevention, treatment, care and support to address HIV/AIDS.

9. Combat stigma and discrimination through the fostering of positive attitudes among health providers and communities towards persons living with HIV and the introduction and enforcement of laws and through regulations that safeguard the rights of affected communities and persons living with HIV.

\section{Gender equality and women's empowerment}

Gender equality underpins all progress and is a prerequisite to the achievement of broader development goals. While many countries in the region have comprehensive laws and policy frameworks in place for promoting gender equality and addressing gender discrimination, there are major gaps in implementation. Deep-rooted structural gender inequity and harmful sociocultural norms and practices persist.

Key actions:

1. Promote gender equality and equity through the adoption and implementation of laws and policies in line with the Convention on the Elimination of All Forms of Discrimination against Women ${ }^{10}$ and other relevant international frameworks.

2. Recognize gender mainstreaming as an important strategy, including genderresponsive budgeting and planning, implementation and monitoring.

3. Strengthen accountability mechanisms for ensuring the full realization of women's sexual reproductive health and rights.

4. Empower women to participate actively in decision-making processes and increase the number of women who hold political office at all levels.

5. Put in place the necessary policies and institutional mechanisms to address exploitation and abuse, including the trafficking of women and children and other harmful practices and forms of discrimination, such as son preference.

${ }^{10}$ United Nations, Treaty Series, vol. 1249, No. 20378. 
6. Invest in men and boys to transform norms and behaviours that perpetuate gender inequities and discriminatory practices and increase men's involvement in and responsibility for enhancing gender equality and the empowerment of women and girls at all levels.

7. Ensure that policies and programmes are guided by the collection, analysis and use of suitably disaggregated data and other evidence on priority concerns and situations of women and men.

\section{E. Violence against women and girls}

Despite progress made, all forms of violence against women and girls remain a major challenge to gender equality and the fulfilment of the rights of women and girls in Asia and the Pacific. The pervasiveness and forms of violence impede the achievement of gender equality and universal reproductive and sexual health and rights, as well as the objectives of the Programme of Action of the International Conference on Population and Development, ${ }^{1}$ the Millennium Development Goals and the Beijing Platform for Action. ${ }^{3}$

Key actions:

1. Promote zero tolerance of violence against women and girls, implement policies to eliminate such violence and the trafficking and exploitation of women and children, and commit to addressing sociocultural norms that are barriers to the empowerment of women and girls.

2. Support national data collection and research on the prevalence, causes and consequences of various forms of violence against women and girls.

3. Monitor reform implementation and the enforcement of laws related to the prevention of and responses to violence against women and girls.

4. Increase the evidence base on violence against women and girls, and apply it to the formulation and revision of policies and programmes.

5. Develop strategies to engage men and boys in the prevention of violence against women and girls.

6. Develop and implement national action plans for the elimination of violence against women and girls, including multisectoral programmes and actions to prevent and address violence against women and girls effectively. 


\section{F. Population ageing}

As a result of declining fertility and mortality, many countries in the region are experiencing a rapid transition in their age structure and face the onset of population ageing. Women comprise the greater number and proportion of older persons and the disparity between the numbers of women and men progressively increases with age.

Key actions:

1. Develop evidence-based policies, plans and programmes to address impact of ageing on economic growth and poverty reduction, taking into consideration the gender aspects of ageing, as well as the rights of the elderly.

2. Enhance national capacities to better understand the implications of population ageing, including the feminization of ageing, public health consequences and the need to expand the traditional scope of public and community health organizations and develop appropriate policies.

3. Ensure that social protection plans are in place to address the needs of the elderly, taking into consideration the specific needs of older women and the most vulnerable among the elderly.

4. Promote the self-reliance of older persons by facilitating their continued participation in economic and social activities at all levels, making full use of their skills and abilities, thereby reducing their dependence on intergenerational transfers.

5. Strengthen the capacity of family caregivers, home-based care and community care, including through the use of volunteers to address the needs of the elderly.

6. Promote adult education, including by providing opportunities within educational programmes for the exchange of knowledge and experience between generations, taking advantage of new technologies.

7. In countries that have yet to undergo the demographic transition:

(a) Conduct an analysis of the age structure over time, including that of the age dependency ratio, in order to guide long-term plans and policies.

(b) Make substantial investments in sectors, including education and employment, in order to take advantage of the demographic bonus. 


\section{G. International migration}

Cross-border and international migration have contributed to the region's economic growth, with remittances increasing income levels. However, migrants rarely have access to basic social and health services, and women are particularly at risk of abuse and exploitation. Trafficking for labour and sexual exploitation is a major concern within the region. Migrants, often with little or no access to health services, are at higher risk of contracting HIV. External migration in some countries is contributing to the loss of skills and capacities in the countries of origin, in many cases leading to critical labour shortages, for example of health workers.

Key actions:

1. Integrate matters relating to international migration into national development strategies, addressing social dimensions and specific issues related to gender.

2. Establish and strengthen systems to collect, analyse and disseminate comprehensive sex-disaggregated data on international migration and ensure that those data are used as a basis for policy formulation and planning processes.

3. Intensify partnership through bilateral and multilateral dialogue to address international migration, in respect of human and labour rights.

4. Adopt and implement appropriate policies and programmes between countries of origin and host countries to protect and provide legal and social services to migrant workers and their families, including sexual and reproductive health and rights, in accordance with the Programme of Action of the International Conference on Population and Development. ${ }^{1}$

5. Work within Asia and the Pacific and the global community to accord special attention to internal and cross-border migrations which are driven by developmentinduced displacement, natural disasters and environmental changes.

\section{H. Emergency preparedness, humanitarian response, transition and recovery}

The Asian and Pacific region faces frequent natural disasters, as well as conflict situations. Not only do these emergencies reverse development progress, they also result in the displacement of populations; the interruption of social and health services, including sexual and reproductive health services; and increased 
vulnerability to gender-based violence, exploitation and abuse. Women and girls have specific needs during crises.

Key actions:

Incorporate reproductive health into the formulation and implementation of gender-sensitive, culturally appropriate national humanitarian preparedness, response and recovery plans, especially those targeting marginalized groups.

\section{Strengthening health systems}

A fully functional, efficient and quality health system is essential for the realization of the Programme of Action of the International Conference on Population and Development ${ }^{1}$ and the health-related Millennium Development Goals, including sexual and reproductive health and reproductive rights. Many countries in the region have health-care systems which are deficient in infrastructure and human resources. Countries should strengthen the capacity of health systems to ensure the availability, accessibility, acceptability and quality of services, with a particular focus on marginalized groups and the poor.

Key actions:

1. Increase and sustain investment for developing and maintaining infrastructure and building a skilled health workforce, especially at the primary health-care level, to address sexual and reproductive health.

2. Promote the collection, publication and dissemination of sex-disaggregated data in line with Millennium Development Goal indicators and focus on data addressing sexual and reproductive health and rights.

3. Facilitate and strengthen policy and programme linkages to integrate sexual and reproductive health and HIV/AIDS and sexually transmitted infection services.

4. Strengthen referral and response systems to ensure the timely and appropriate provision of services for sexual and reproductive health.

5. Strengthen evidence-based monitoring and evaluation systems at all levels on maternal and neonatal health, as well as reproductive health and family planning.

6. Develop and implement policies and programmes for the retention of the skilled health workforce that is vital for achieving the Programme of Action of the International Conference on Population and Development. ${ }^{1}$ 
7. Ensure the availability, accessibility and affordability of quality maternal health services.

\section{J. Partnerships}

Key actions:

1. Strengthen collaboration and coordination among Governments, donors, non-governmental organizations, civil society, the private sector and other sectors in the implementation of sexual and reproductive health and reproductive rights.

2. The international community should expedite action to assist countries in staying on course for achieving the Millennium Development Goals, including through gender-sensitive and gender-responsive policies.

3. Donors should increase levels of development assistance, consistent with their commitments to developing countries, in order to ensure sustainability and achievement of the Millennium Development Goals.

4. All development partners should take speedy action to meet their commitments to the Paris Declaration on Aid Effectiveness ${ }^{11}$ and the Accra Agenda for Action $^{12}$ to ensure development effectiveness.

In conclusion, we, the delegates of the Asia-Pacific High-level Forum on ICPD at 15 , reaffirm our commitment to the promotion of the human rights of all the people of this region and to ensuring their access to the highest attainable standard of health, in the context of sustainable development. We end our Forum determined to implement the key actions contained in this Declaration in order to complete the unfinished agenda of the International Conference on Population and Development.

\footnotetext{
${ }^{11}$ Paris Declaration on Aid Effectiveness: Ownership, Harmonization, Alignment, Results and Mutual Accountability, adopted at the High-level Forum on the question of "Joint Progress towards Enhanced Aid Effectiveness: Harmonization, Alignment, Results", held in Paris from 28 February to 2 March 2005 (see http://www.worldbank.org/harmonization/PARIS/FINALPARISDECLARATION.pdf).

${ }^{12} \mathrm{~A} / 63 / 539$, annex.
} 